Review

\title{
Recent developments in metal phosphide and sulfide electrocatalysts for oxygen evolution reaction
}

\author{
Lishan Peng, Syed Shoaib Ahmad Shah, Zidong Wei * \\ School of Chemistry and Chemical Engineering, Chongqing University, Chongqing 400044, China
}

\section{A R T I C L E I N F}

\section{Article history:}

Received 30 May 2018

Accepted 3 July 2018

Published 5 October 2018

\section{Keywords:}

Oxygen evolution reaction

Electrocatalysis

Metal phosphide

Metal sulfide

In situ oxidation

Active component

\begin{abstract}
A B S T R A C T
Oxygen evolution reaction (OER), as an important half-reaction involved in water splitting, has been intensely studied since the last century. Transition metal phosphide and sulfide-based compounds have attracted increasing attention as active OER catalysts due to their excellent physical and chemical characters, and massive efforts have been devoted to improving the phosphide and sulfide-based materials with better activity and stability in recent years. In this review, the recent progress on phosphide and sulfide-based OER electrocatalysts in terms of chemical properties, synthetic methodologies, catalytic performances evaluation and improvement strategy is reviewed. The most accepted reaction pathways as well as the thermodynamics and electrochemistry of the OER are firstly introduced in brief, followed by a summary of the recent research and optimization strategy of phosphide and sulfide-based OER electrocatalysts. Finally, some mechanistic studies of the active phase of phosphide and sulfide-based compounds are discussed to give insight into the nature of active catalytic sites. It is expected to indicate guidance for further improving the performances of phosphide and sulfide-based OER electrocatalysts.
\end{abstract}

(C) 2018, Dalian Institute of Chemical Physics, Chinese Academy of Sciences. Published by Elsevier B.V. All rights reserved.

\section{Introduction}

Growing society concerns has been focused on the environmental pollution and global energy crisis caused by consumption of fossil fuels. Hydrogen $\left(\mathrm{H}_{2}\right)$, with high energy density, small molecular mass and only clean water as the combustion product, is regarded as an ideal energy carrier for future energy storage and supply [1-5]. In addition, $\mathrm{H}_{2}$ is also a critical chemical feedstock in the modern industry, for example, in synthesis of ammonia for fertilizer and hydrocracking in petroleum refining [6]. At present, the main strategy adopted to produce hydrogen is the steam reforming process from fossil resources, which uses both $\mathrm{H}_{2} \mathrm{O}$ and $\mathrm{CH}_{4}$ as the primary source for large-scale production of $\mathrm{H}_{2}$. However, this production route not only aggravates the consumption of fossil fuels, but also contributes to the global $\mathrm{CO}_{2}$ emission [7,8]. Therefore, there is an urgent need to search a clean, renewable and efficient route for $\mathrm{H}_{2}$ production.

With a number of advantages such as using abundant water as starting material, no emission of greenhouse gases and other polluted gases, high hydrogen production efficiency and high-purity product, electrochemical water splitting for hydrogen and oxygen production is considered as a promising approach to provide affordable clean energy if renewable energy or surplus electricity is fully available [6]. Electrocatalytic water splitting, which is a reverse process of fuel cell reactions, involves the cathodic hydrogen evolution reaction (HER), and the anodic oxygen evolution reaction (OER). Compared to the

\footnotetext{
*Corresponding author. Tel: +86-23-65678928; E-mail: zdwei@cqu.edu.cn

This work was supported by the National Key Research and Development Program of China (2016YFB0101202) and the Key Program of National Natural Science Foundation of China $(91534205,21376283,21576032)$.

DOI: 10.1016/S1872-2067(18)63130-4 | http://www.sciencedirect.com/science/journal/18722067 | Chin. J. Catal., Vol. 39, No. 10, October 2018
} 
more developed HER catalysts, OER catalysts is more complex and challenging [9]. Actually, as for the HER, which is based on a two-electron transfer $\left(2 \mathrm{e}^{-}\right)$, it proceeds at a high rate in acidic conditions, where plenty of protons are available. In alkaline conditions, the scanty proton make the HER kinetics comparatively more sluggish, and its reaction rate directly depends on the anodic OER which supplies the protons to the cathode by the deprotonation of hydroxide ions. On the other hand, the OER, which involves a four sequential electron transfer mechanism ( $\left.4 \mathrm{e}^{-}\right)$as well as oxygen-oxygen bond formation, is a complicated and sluggish process, affecting the overall Faradaic efficiency of the electrolysis cell to a greater extent [10].

In practice, an electrolysis cell can never be performed under the theoretical decomposition potential because of various thermodynamic and kinetic hindrances. The absolute difference between the experimental potential and the thermodynamical potential is named as overpotential. Additional energy is demanded to overcome the overpotential, which is caused by polarization of various electrode processes. In order to ensure the electrolyzer practically efficient, both reactions require active and robust electrocatalysts to accelerate reaction process and finally reduce the electrolysis overpotential. Precious metal oxides $\left(\mathrm{IrO}_{2} / \mathrm{RuO}_{2}\right)$ possess the best performance (activity and durability) for the OER, while large-scale industrial application of an electrolyzer has been impeded by their high cost and scarcity $[11,12]$. In order to speed up the industrialization of electrocatalytic water splitting and lower its industrial cost, numerous efforts have been stimulated to search for new electrocatalysts based on noble metals free elements [13]. Fortunately, nowadays there are increasingly many reports that claim that transition metal oxides, sulfides, selenides, nitrides, phosphides, and so forth are also highly efficient OER catalysts [14-24]. Among them, metal phosphide and sulfide electrocatalysts show super-activity for OER even as good as the traditional $\mathrm{IrO}_{2}$ benchmark OER catalyst in alkaline media [25-28]. Therefore, it is necessary to summarize the new progress in this aspect.

In this review, after a brief description of the reaction mechanisms of OER in alkaline and acid electrolytes, we discuss the main barriers against accelerating the kinetic and thermodynamic process of OER in terms of activity. We try to categorize the findings reported in the literatures to provide a picture about metal phosphide and sulfide electrocatalysts for OER. The influence of some of important parameters, such as electrical conductivity, mass transport, active area and interface chemistry etc., on OER activity is discussed and commended. Then, the dominant role of less studied in situ evolution surface of metal phosphide and sulfide electrocatalysts is further summarized, which essentially include the catalytic property of metal cations and oxide/hydroxide anions in terms of the nature of true catalytic sites. Finally, we try to outline the further direction to facilitate the property of phosphide and sulfide catalysts for OER.

\section{Reaction mechanisms and thermodynamics of the OER}

An electrolyzer for electrocatalytic water splitting has four component parts: an electrolyte, a diaphragm, a cathode and an anode. In order to speed up the electrocatalytic water splitting reaction, hydrogen evolution catalysts (HEC) and oxygen evolution catalysts (OEC) are coated on the cathode and anode, respectively $[29,30]$. Although the thermodynamic potential for the electrocatalytic water splitting is $1.23 \mathrm{~V}$ under standard conditions $\left(25^{\circ} \mathrm{C}\right.$ and $\left.1 \mathrm{~atm}\right)$, an overpotential is required in a practical process. When an external voltage is applied to the electrodes, water molecules are decomposed and oxidized into oxygen at anode, meanwhile electron and proton combine to form hydrogen at cathode [31]. The hydrogen can be stored as fuels and the oxygen is released into the atmosphere. As stated in the introduction, though the production of purest $\mathrm{H}_{2}$ is the main objective, more attention should be pay to the counter-reaction (OER), as it is one of several bottlenecks for the electrocatalytic water splitting and decides the overall Faradaic efficiency of the electrolytic cell.

In general, the electrochemical reaction occurred at the anode is proceeded via several proton/electron-coupled procedures [9]. The OER is highly $\mathrm{pH}$ sensitive, and the kinetics of the OER is quite different in acidic to alkaline media. In acidic and neutral conditions, two water molecules $\left(\mathrm{H}_{2} \mathrm{O}\right)$ are oxidized into four protons $\left(\mathrm{H}^{+}\right)$and oxygen molecule $\left(\mathrm{O}_{2}\right)$, while hydroxyl groups $\left(\mathrm{OH}^{-}\right)$are oxidized and transformed into $\mathrm{H}_{2} \mathrm{O}$ and $\mathrm{O}_{2}$ in basic conditions. However, the anode catalysts for catalyzing OER in acid condition are mainly based on the precious $\mathrm{Ir}, \mathrm{Ru}$ metals and their oxides. Other metals and their derived materials are not suitable for using as OER electrocatalysts due to their poor anti-acid corrosion [32-34]. Accordingly, almost all the metal phosphide and sulfide based materials are applied as OER electrocatalysts in alkaline electrolytes. In 1986, a detailed review on various reported OER mechanisms in acidic and alkaline media were reported by Matsumoto and Sato [35], including the Krasil'shchkov, Bockris [36], Yeager, and Wade [37] pathways in addition to the electrochemical oxide pathway [38]. Nowadays, the most recognized OER partway in alkaline media are shown as follows:

$$
\begin{gathered}
\mathrm{M}+\mathrm{OH}^{-} \rightarrow \mathrm{M}-\mathrm{OH}_{\mathrm{ads}}+\mathrm{e}^{-} \\
\mathrm{M}-\mathrm{OH}_{\mathrm{ads}}+\mathrm{OH}^{-} \rightarrow \mathrm{M}-\mathrm{O}_{\mathrm{ads}}+\mathrm{H}_{2} \mathrm{O}+\mathrm{e}^{-} \\
\mathrm{M}-\mathrm{O}_{\mathrm{ads}}+\mathrm{M}-\mathrm{O}_{\mathrm{ads}} \rightarrow 2 \mathrm{M}+\mathrm{O}_{2} \\
\text { or } \mathrm{M}-\mathrm{O}_{\mathrm{ads}}+\mathrm{OH}^{-} \rightarrow \mathrm{M}-\mathrm{OOH}_{\mathrm{ads}}+\mathrm{e}^{-} \\
\mathrm{M}-\mathrm{OOH}_{\mathrm{ads}}+\mathrm{OH}^{-} \rightarrow \mathrm{M}+\mathrm{O}_{2}+\mathrm{H}_{2} \mathrm{O}+\mathrm{e}^{-}
\end{gathered}
$$

where, $\mathrm{M}$ represents the active site of catalyst surface, and "ads" is the adsorption species on the catalyst surface. All of the proposed mechanisms begin with an essential elementary step of hydroxide coordination to the active site under alkaline conditions, and then proceed via two main pathways with different proposed other elementary steps [36]. The first one is the direct coupling of two $\mathrm{M}-\mathrm{O}_{\text {ads }}$ intermediates, processing through the steps of $(1) \rightarrow(2) \rightarrow(3)$. In the second pathway via $(1) \rightarrow(2) \rightarrow(4) \rightarrow(5)$, intermediate M-OOHads is formed at first by the reaction of $\mathrm{M}-\mathrm{O}_{\text {ads }}$ with $\mathrm{OH}^{-}$, and subsequently combined with another $\mathrm{OH}^{-}$to produce $\mathrm{O}_{2}$. In general, the thermodynamic barrier of Reaction (3) is always larger than those of reactions (4) and (5).

As for metal phosphides and sulfides, the OER reaction generally go through the second pathway [39]. The overpotential 
required for an OER catalyst is commonly decided by the highest kinetic activation barrier of the individual reaction steps. While the actual reaction process and rate-determining step for the OER are determined by the catalytic material and reaction conditions it occurred. The determination of the free energy change of each step gains good insight into how to accelerate the reaction rate and further offers directions for the design and synthesis of electrocatalysts. Gibbs free energy is a key descriptor to evaluate whether reactions go through spontaneously. To construct the reaction pathway for the OER, the calculation of the Gibbs free energy in comparison to the reference energy level $(\Delta G)$ is of the essence. The reaction free energy of the reaction steps of metal phosphide and sulfide, i.e., Eqs. (1), (2), (4), and (5) can be described by the equations below:

$$
\begin{gathered}
\Delta G_{1}=\Delta G^{*} \mathrm{OH}_{\mathrm{H}}-\mathrm{e} U+\Delta G_{\mathrm{H}+}(\mathrm{pH}) \\
\Delta G_{2}=\Delta G^{*}-\Delta G^{*} \mathrm{OH}-\mathrm{e} U+\Delta G_{\mathrm{H}+}(\mathrm{pH}) \\
\Delta G_{4}=\Delta G^{*} \mathrm{OOH}-\Delta G^{*} \mathrm{O}-\mathrm{e} U+\Delta G_{\mathrm{H}+}(\mathrm{pH}) \\
\Delta G_{5}=4.92-\Delta G^{*} \mathrm{OOH}-\mathrm{e} U+\Delta G_{\mathrm{H}+}(\mathrm{pH})
\end{gathered}
$$

As the reaction free energy of whole OER process is confirmed, the free energy diagram on different catalysts can be plotted against reaction route by assigning the absolute free energy of first stage of OER to zero. The reaction free energy of Eqs. (6)-(9) are determined by adsorption free energy of oxygen-containing intermediates. The Gibbs free energy differences of these various oxygenated species ( $a t \mathrm{U}=0$ and $\mathrm{pH}=0$ ) can be calculated by equations below:

$$
\begin{gathered}
\Delta G * \mathrm{OH}=\mathrm{G}^{*} \mathrm{OH}+1 / 2 \mathrm{G}_{\mathrm{H} 2}-\mathrm{G}^{*}-\mathrm{G}_{\mathrm{H} 2 \mathrm{O}} \\
\Delta G^{*}=\mathrm{G}^{*} \mathrm{O}+\mathrm{GH}_{2}-\mathrm{G}^{*}-\mathrm{G}_{\mathrm{H} 2 \mathrm{O}} \\
\Delta G^{*} \mathrm{OOH}=\mathrm{G}^{*} \mathrm{OOH}+3 / 2 \mathrm{GH}_{2}-\mathrm{G}^{*}-2 \mathrm{GH}_{2 \mathrm{O}} \\
\Delta G_{\mathrm{O} 2}=\mathrm{G}_{\mathrm{O} 2}+2 \mathrm{G}_{\mathrm{H} 2}-\mathrm{G}^{*}-2 \mathrm{G}_{\mathrm{H} 2 \mathrm{O}}
\end{gathered}
$$

By feat of the free energy diagram, a very important parameter i.e., the potential-determining step can be deduced to estimate which step suffers the most sluggish process during the overall reaction. More precisely, the catalytic performance is decided by the magnitude of the potential-determining step for the OER. In other words, the overpotential is limited by the step with the maximum change of the Gibbs free chemisorption energy of two subsequent adsorbed intermediates. This was the last step to become downhill in free energy as the potential increased, that is, the specific reaction step in the four-step mechanism with the largest $\Delta G$ (Eq. (14)):

$$
G_{\text {OER }}=\max \left[\Delta G_{1}, \Delta G_{2}, \Delta G_{4}, \Delta G_{5}\right]
$$

The theoretical overpotential, which is independent of $\mathrm{pH}$, is then given by Eq. (15):

$$
\eta=\max \left[\Delta G_{1}, \Delta G_{2}, \Delta G_{4}, \Delta G_{5}\right] / \mathrm{e}-1.23 \mathrm{~V}
$$

In an ideal case, all the four charge transfer steps have reaction free energies of the same magnitude at zero potential (4.92 $\mathrm{eV} / 4=1.23 \mathrm{eV}$ ). This is equivalent to all the reaction free energies being zero at the equilibrium potential, $1.23 \mathrm{~V}$, which indicates that there is no overpotential derived from thermodynamic hindrance. An ideal catalyst is required to be capable to facilitate water oxidation just above the equilibrium potential. The catalyst that fulfills this requirement is thermochemically ideal, but is conspicuously absent in reality. In fact, even for the most active $\mathrm{RuO}_{2}$ catalyst, a large free energy difference of 1.60 $\mathrm{eV}$ was found in the third step where the second water mole- cule was decomposed. These results indicated that at potentials above $1.60 \mathrm{~V}$, all reaction steps of the OER (over $\mathrm{RuO}_{2}$ ) are exothermic [40]. Besides, the theoretical and experimental values have large difference in the standard free energy change associated with the elementary step. This is attributed to that the kinetic hindrances are not considered in the thermodynamic prediction of the overpotential. From an experimental viewpoint, the magnitude of Tafel slope is often used as a direct evidence to identify the rate-determining step [41].

\section{Metal phosphide and sulfide based materials for OER}

\subsection{Metal phosphides}

In 1990s, metal phosphides were firstly reported as OER electrocatalysts by Kupka et al. [42]. Amorphous structure Ni-Co-P alloys were obtained by electrodepositing under galvanostatic conditions and further were heated at $500{ }^{\circ} \mathrm{C}$ to form crystalline Ni-Co-P alloys. Electrochemical results show that the activities of both crystalline and amorphous phases were almost similar. Interestingly, it was also found that the Ni-Co-P alloys were oxidized to form oxyhydroxides on its surface, which may exert a specific influence on the electrocatalytic effect. After this work, the research on metal phosphides seems to be depressed. Until 2015, Yoo et al. [43] made a further progress on confirming the true catalytic site of the metal phosphides was not the bulk phase phosphide but its surface oxidized compounds. Inspired by this work, extensive studies on metal phosphides for OER in the past decade have been reported, such as $\mathrm{TP}$ and $\mathrm{T}_{2} \mathrm{P}(\mathrm{T}=\mathrm{Fe}$, Co and $\mathrm{Ni})$ and so forth [43-50]. To achieve a high-energy efficiency, the researchers were mainly devoted their efforts to improving the catalytic activity and stability.

It is well known that the catalytic activity of a catalyst is significantly affected by the density of active sites. Realizing the exposure of active sites is an effective way to achieve an enhancement in electro-reaction performance [55-64]. In the last 10 years, most of these catalyst preparations are based on nanoparticles that show a high surface area, but also have some disadvantages such as uncontrolled agglomeration, higher series resistances, still-existing templates, and easier oxidation. Nanostructuring these catalysts can help with their excellent structure rigidity to prevent aggregation and, consequently, significant enhancement in their durability for various applications. Today, many well-aligned metal phosphide nanostructures have been successfully synthesized by different methods [65]. As shown in Fig. 1(a)-(c), Oh et al. [51] used a facile one-step electrodeposition to synthesize a porous Co-P foam structure. Compared with the Co-P film, the 3-D Co-P foam catalyst exhibits a lower overpotential $(300 \mathrm{mV})$ reported at 10 $\mathrm{mA} \mathrm{cm}{ }^{-2}$ in alkaline solution with excellent long-term stability. The authors ascribed the excellent performance of the Co-P foam to the charge separation between Co and P in Co-P foam as well as the porous foam structure providing a large electrochemically active surface area (ECSA). Besides the porous structure, morphology of catalytic nanostructures, such as nanowire, nanorods, nanotube, nanobush, and so on, also have 


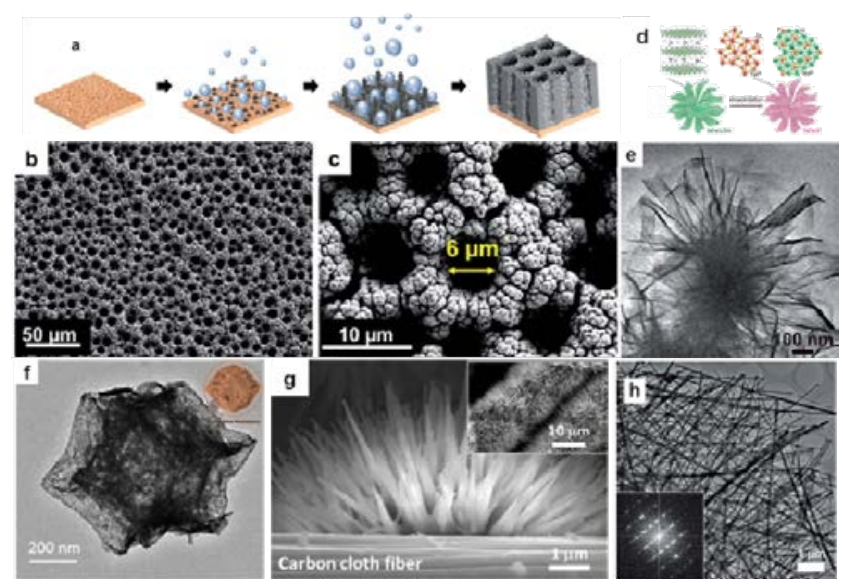

Fig. 1. (a) A schematic illustration of the synthesis of the Co-P foam. Surface SEM images of the Co-P foam at 400 (b) and 3200 (c) magnification [51]. (c) The Royal Society of Chemistry 2016. (d, e) Synthesis procedure and SEM image of the flower-like NiFe-P [52]. (C) The Royal Society of Chemistry 2018. (f) SEM image of CoP hollow polyhedron [46]. (C) 2015 American Chemical Society. (g) SEM image of CoP nanoneedles arrays [53]. (c) 2016 Wiley-VCH Verlag GmbH \& Co. KGaA, Weinheim. (h) TEM image of CoP NWs [54]. (c) The Royal Society of Chemistry 2017.

significant effects on catalyst's activity [55-57,63,66-68]. Wang et al. [53] reported CoP-based nanoneedle arrays supported on carbon cloth (Fig. 1(g)) as a highly active catalyst for both OER and HER, and found that the nanoarray morphology has significant contribution to the activity. Liu et al. [46] developed regular hollow polyhedral cobalt phosphide (CoP hollow polyhedron, Fig. 1(f) electrocatalysts for HER and OER templated by Co-centered MOFs through simple oxidation and phosphorization calcinations. Later, Li et al. [54] synthesized monolithic electrodes covered with dense single-crystalline CoP nanowires (CoP NWs, Fig. 1(h)) through a one-step thermal phosphorization treatment of porous metallic Co foam using red phosphorous. All these nanostructures of cobalt phosphides show efficient catalytic ability due to their high specific surface area and superior charge transfer ability.

Electroconductivity is an important parameter for electrocatalytic reaction as it can effectively affect the electron and proton transfer during the OER process. Increasing the intrinsic conductivity of the phosphide materials is a direct strategy to promote their catalytic performances for OER. It is widely known that the phosphide materials are good electrical conductors [25]. However, the conductivity of phosphides changes along with the crystal structure and stoichiometric form. Blanchard et al. [69] discovered that the metal-rich phosphides had less ionic character and more metallic character through X-ray photoelectron and absorption spectroscopy (XPS) along with a charge potential model. With no doubt, the metal-rich phosphides exhibited higher catalytic activity than corresponding monometallic phosphides (Fig. 2(a)-(c)). Very recently, Jin and co-workers [70] observed a similar phenomenon in the case of cobalt phosphide. Two different kinds of cobalt phosphide $\left(\mathrm{CO}_{2} \mathrm{P}\right.$ and $\left.\mathrm{CoP}\right)$ were prepared with the same morphology assisted by a rapid microwave preparation. Comparing with the $\mathrm{CoP}$ nanowires, the metallic $\mathrm{Co}_{2} \mathrm{P}$ nanowires show the advanced efficiency for the overall water splitting due to its metallic properties with improved conductivity (Fig. 2(d)-(h)).

Combining the metal phosphides with conducting metal supports is another efficient method to enhancing electroconductivity of the catalysts. Actually, merging catalysts with conducting substrates can not only improve electronic conductivity, but also expose more active sites. For examples, growth of $\mathrm{CoP}$ mesoporous nanorod arrays on conductive Ni foam exhibited an overpotential value of $290 \mathrm{mV}$ for driving a $10 \mathrm{~mA} \mathrm{~cm}^{-2}$ for OER, superior than that of noble metal benchmark $\mathrm{IrO}_{2}$ (Fig. 3(a)-(c)) [71]. This is intimately related to the unique nanorod array electrode configuration, leading to excellent electric interconnection and improved mass transport. In a similar approach, 3D ternary nickel-iron phosphide microflowers with a hierarchically porous morphology was directly grown on $\mathrm{Ni}$ foam as OER catalyst (Fig. 3(d)-(f)) [72]. Beside the Ni substrate, many other conductive metals have also widely reported as catalystic substrates, such as Co foil, Ti mesh, $\mathrm{Cu}$ foam and even stainless steel foil [75,76]. Yuan et al. [77] reported the first example of cobalt-rich cobalt phosphide catalysts directly grown on cobalt foil (denoted as $\mathrm{Co}_{2} \mathrm{P} / \mathrm{Co}$-foil) as a novel non-noble metal and integrated electrode by one-step phosphorization of a pre-oxidized Co foil. Xie et al. [78] used Ti mesh to support Co-Pi nanoarray and its cobalt phosphide precursor. Hou and coworkers [79] reported the cedar like semimetallic $\mathrm{Cu}_{3} \mathrm{P}$ nanoarrays directly grown on 3D copper foam substrate as highly effective OER electrocatalysts.

Materials grown on carbon based materials drew attention of the community due to its high conductivity and anti-corrosive quality for both acid and alkaline environments [53,73,80-83]. Conversely, abundant functional groups generated on the surface of carbon materials allows excellent dispersity of electrocatalysts, attributing to the full use of active sites on catalysts $[74,84,85]$. Wang and co-worker [73] fabricated a self-supported Ni-P on carbon fiber paper (CP@Ni-P) by electrodeposition of $\mathrm{Ni}$ on functionalized $\mathrm{CP}$, followed by a convenient one-step phosphorization in phosphorus vapors at $500{ }^{\circ} \mathrm{C}$ (Fig. 3(h) and (i)). The as-fabricated CP@Ni-P electrode exhibited excellent electrocatalytic performance toward hydrogen and oxygen evolution, with only small overpotentials of 250 and $300 \mathrm{mV}$, respectively, attaining a current density of $100 \mathrm{~mA}$ $\mathrm{cm}^{-2}$ in cathode and $50.4 \mathrm{~mA} \mathrm{~cm}^{-2}$ in anode and remained stable at 10 and $20 \mathrm{~mA} \mathrm{~cm}-2$ over $100 \mathrm{~h}$ (Fig. 3(j) and (k)). In a different method for convenience, Zheng et al. [81] developed a one-step electrodeposition to directly obtain the $\mathrm{NiP}_{x}$ on carbon fiber. Apart from the carbon fiber, significant catalytic activity enhancements were observed as the material is grown on highly conductive carbon nanotube (CNT). Chen and co-workers [74] have proven that the activity of the CoP-CNT was superior to that of $\mathrm{Co}_{3} \mathrm{O}_{4}-\mathrm{CNT}, \mathrm{CoP}$, and even state-of the-art catalyst $\mathrm{RuO}_{2}$ (Fig. 3(l) and (m)). Likewise, porous FeP nanorods grafted on CNT backbones were further reported as excellent OER catalysts [84]. In addition, the attractive graphene material has been used to hybridize with phosphides to enhance its electrocatalytic activity, such as the superior catalytic activity of $\mathrm{NiCoP} / \mathrm{rGO}$ hybrids boosted by their hybridization with rGO that accelerates the charge transfer [85]. In a 
a

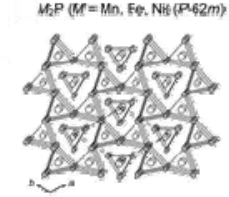

b

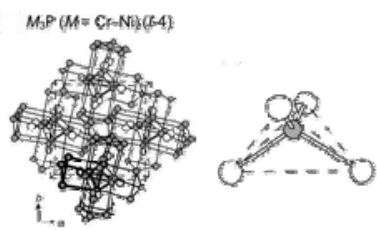

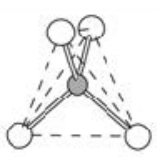
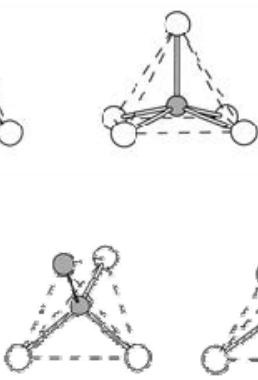
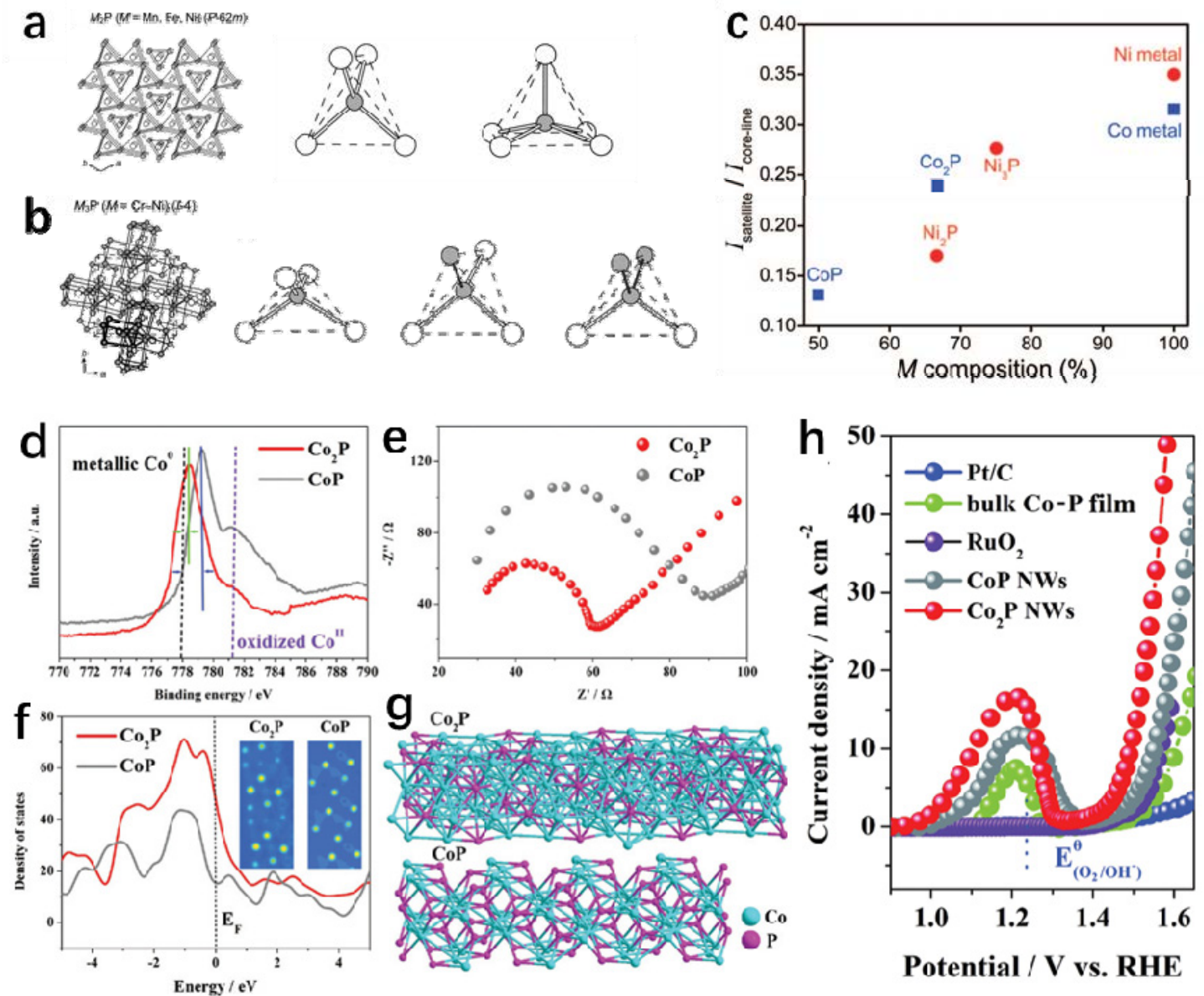

Potential / V vs. RHE

Fig. 2. Structures of metal-rich phosphides and coordination environments around $M$ atoms in (a) $\mathrm{M}_{2} \mathrm{P}$ and (b) $\mathrm{M}_{3} \mathrm{P}(\mathrm{M}=\mathrm{Cr}-\mathrm{Ni})$ in terms of $\mathrm{P}$-centered $\mathrm{M}_{6}$ trigonal prisms. The small shaded circles are $\mathrm{M}$ atoms and the large open circles are P atoms. (c) Plot of normalized satellite intensity ( $I_{\text {satel- }}$ lite/ $I_{\text {core-line) }}$ vs $M$ composition in Co and Ni phosphides, and the elemental metals [69]. (C) 2008 American Chemical Society. (d) XPS spectra of Co $2 p_{3 / 2}$. (e) Nyquist plots of EIS; (f) Calculated DOS and inset is the electron density distribution of the crystal plane of (020). (g) The supercell models of the two materials. (h) Polarization curves of the catalysts for water oxidation in 1 mol/L KOH [70]. (C) The Royal Society of Chemistry 2016.

word, compositing catalyst with carbon materials can make full use of the excellent conductivity and dispersity of carbon materials, and finally benefits the electrocatalytic activity.

For four electrons water oxidation reaction, a catalyst containing multiple redox-active metal ions can buffer the multi-electron transfer processes necessary for OER [86]. Metal doping seems as an effective strategy to achieve the purpose that multiple redox-active metal ions exist in the OER catalysts [85,87-95]. Li and co-workers [89] successfully synthesized the homogeneous ternary $\mathrm{Fe}_{2-x} \mathrm{Mn}_{x} \mathrm{P}$ nanorods with control of $\mathrm{Mn}$ incorporation $(0 \leq x \leq 0.9)$ from the solution-phase reaction of manganese and iron carbonyl complexes with trioctylphosphine. After an initial decrease between $x=0$ $\left(\mathrm{Fe}_{2} \mathrm{P}\right)$ and $x=0.2$, the OER activity of $\mathrm{Fe}_{2-x} \mathrm{Mn}_{x} \mathrm{P}$ nanorods dramatically increased with the incorporation of Mn (overpotential as low as $0.44 \mathrm{~V}$ at $10 \mathrm{~mA} / \mathrm{cm}^{2}$ for $x=0.9$ (Fig. 4(a) and (b)). These results suggest that the stoichiometry of bimetallic phosphides is a key determiner of activity, reflecting either electronic modulation of the active site or the participation of multiple metal sites to achieve water oxidation and $\mathrm{O}_{2}$ formation and/or release. Not only $\mathrm{Fe}_{2} \mathrm{P}$ but also Co, Ni based phosphides were also found to enhance the activity by introduce a suitable second metal element. Wang et al. [92] carried out a Fe doped $\mathrm{Ni}_{2} \mathrm{P}$ for water splitting, and $\mathrm{Ni}_{1.85} \mathrm{Fe}_{0.15} \mathrm{P}$ showed higher activity than $\mathrm{Ni}_{2} \mathrm{P}$ (Fig. 4(c)). Further, Chen and co-workers [93] synthesized a series of $\mathrm{Fe}$ doped $\mathrm{Ni}_{2} \mathrm{P}$ with different $\mathrm{Fe}$ contents, and found $\left(\mathrm{Ni}_{0.87} \mathrm{Fe}_{0.13}\right)_{2} \mathrm{P}-\mathrm{Ni}$ composite exhibits the highest catalytic activity toward OER in alkaline solution among all the as-prepared $\left(\mathrm{Ni}_{1-x} \mathrm{Fe}_{x}\right)_{2} \mathrm{P}-\mathrm{Ni}$ catalysts. In another case, the CoP doped by Fe were reported by two different research groups $[91,95]$, and both of which were observed to be more efficient than the pristine CoP compound. Interestingly, Zhang et al. [87] revealed the insert $\mathrm{Al}$ can be utilized as an effective dopant to influence the electronic structure of CoP (Fig. 4(f)). The effect was so apparent that a suitable secondary metal with any dopant amount of incorporation drastically changed the activity of the system.

Understanding the origin of dopant induced change in catalytic activity for OER is significant for further design and synthesis of the phosphide-based catalysts. Based on the present evidences, the activity enhancement of metal phosphides might be ascribed to the modulated binding energy of O-containing 

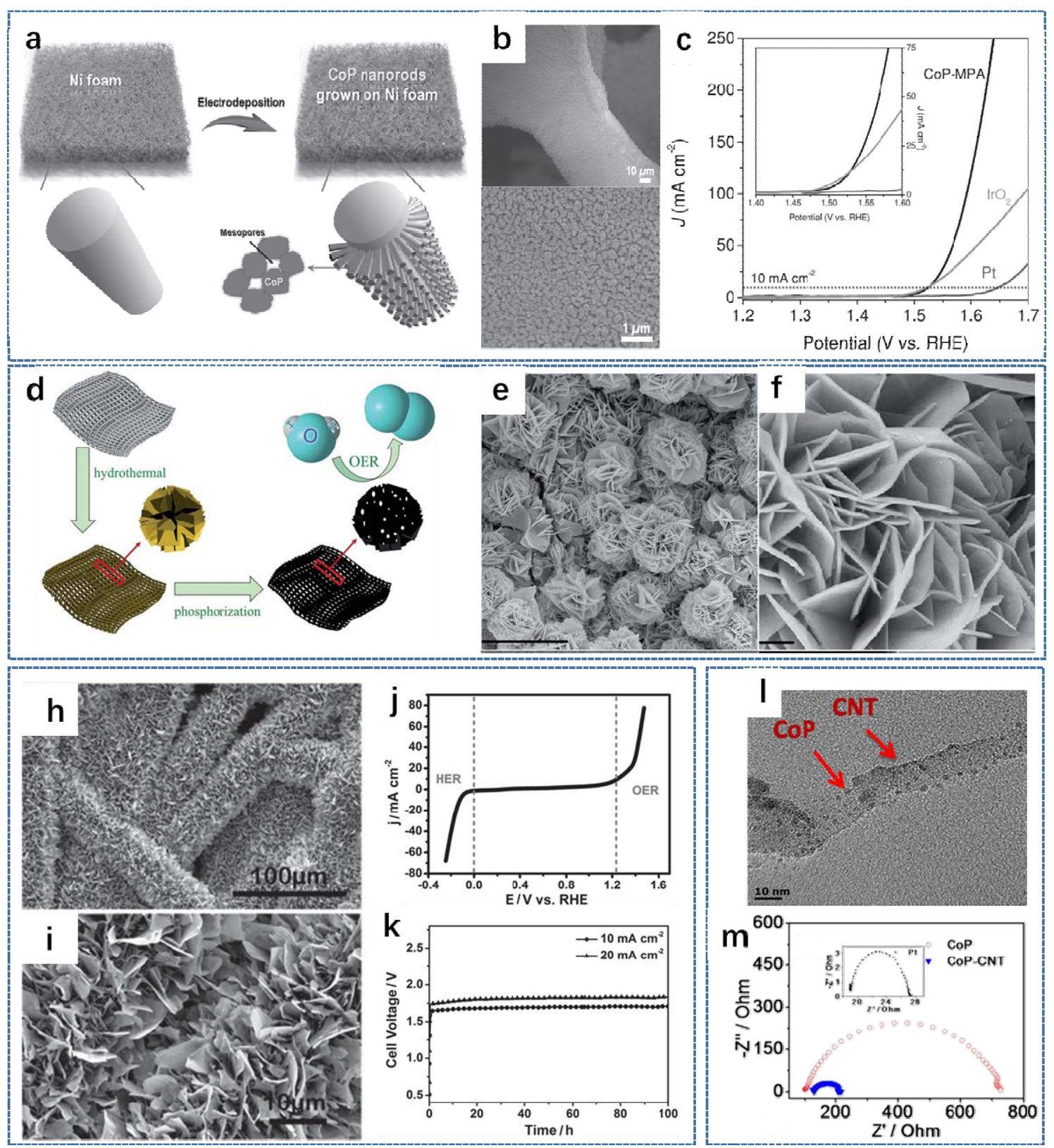

Fig. 3. (a) Schematic illustration of the fabrication of CoP mesoporous nanorods arrays. (b) SEM images of CoP-MNA. (c) LSV polarization curves (2 $\mathrm{mV} \mathrm{s}^{-1}$ in $\mathrm{O}_{2}$ saturated $1 \mathrm{~mol} / \mathrm{L} \mathrm{KOH}$ ) and b) Tafel plots of CoP-MNA, IrO , and Pt for electrocatalytic OER [71]. (C) 2015 WILEY-VCH Verlag GmbH \& Co. KGaA, Weinheim. (d) Schematic illustration of the $\left(\mathrm{Ni}_{x} \mathrm{Fe}_{1-x}\right)_{2} \mathrm{P}$ fabrication process. (e, f) SEM images of $\left(\mathrm{Ni}_{0.5} \mathrm{Fe}_{0.5}\right)_{2} \mathrm{P}$ microflowers. [72] (c) The Royal Society of Chemistry 2017. (h) Low- and (i) high-magnifi cation SEM images of CP@Ni-P. (j) Polarization curve recorded in a three-electrode configuration in a wide potential window ( -0.24 to $1.47 \mathrm{~V}$ versus RHE) showing the bifunctionality of CP@Ni-P toward both HER and OER. (k) Long-term

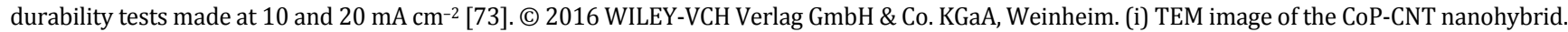
(m) Nyquist plots of electrochemical impedance spectra of the as-prepared CoP, CoP-CNT, Pt (inset) at $\eta=340 \mathrm{mV}$ [74]. () 2015 American Chemical Society.

intermediates and improved conductibility [20,25,26,97]. However, the exact cause of the enhancement is still a mystery. Alloying provides a means for mixing a wide range of elements and studying the synergistic effects. Liu et al. [96] developed a facile and scalable method to synthesize hollow and conductive iron-cobalt phosphide (Fe-Co-P) alloy nanostructures using a Fe-Co metal organic complex as a precursor (Fig. 4(g)). The Fe-Co-P alloy exhibits excellent OER activity with a specific current density of $10 \mathrm{~mA} / \mathrm{cm}^{2}$ being achieved at an overpotential as low as $252 \mathrm{mV}$ (Fig. 4(h)). Further mechanistic studies and theoretical analysis suggest that the electrochemical-induced high-valent iron stabilizes the cobalt in a low-valent state, leading to the simultaneous enhancement of activity and stability of the OER catalyst. This is a step forward to uncover the root of dopant induced change in catalytic activity, while definitely establishing a mechanistic concept for these newly emerging phosphide OER materials certainly need more experimental with elaborated methodology.

It can be noted that the surface state of the electrocatalysts also plays a crucial role in determining the electrocatalytic re- 

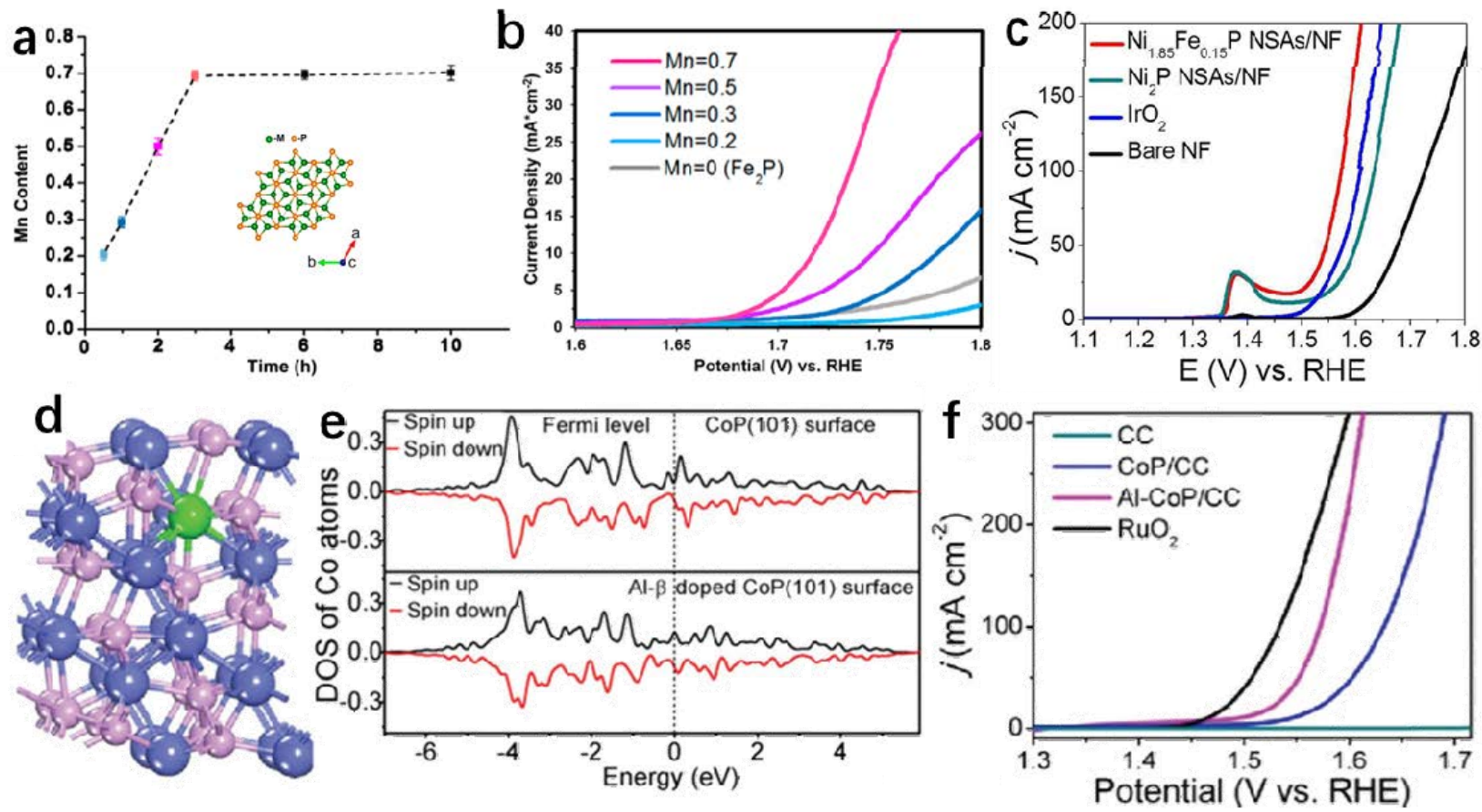

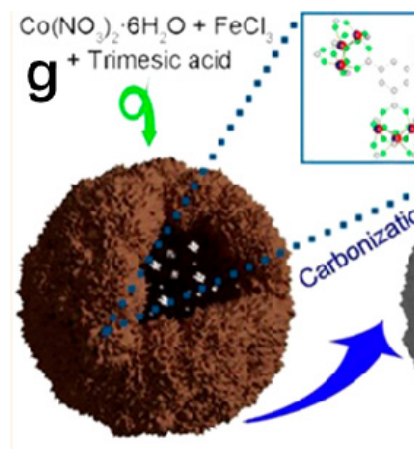

Fe/Co MOC Hollow Spheres

$\mathrm{Fe} / \mathrm{Co} / \mathrm{C}$ Hollow Spheres

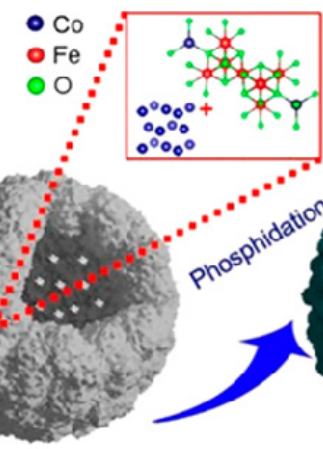

Fe-Co-P Alloy Hollow Spheres

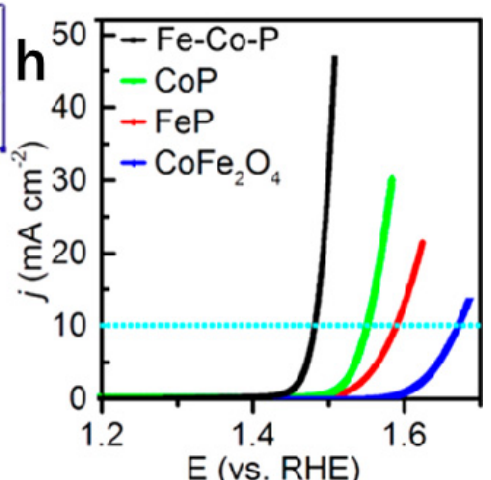

Fig. 4. (a) Mn uptake in $\mathrm{Fe}_{2-x} \mathrm{Mn}_{x} \mathrm{P}$ as a function of reaction time. (b) Polarization curves as a function of composition, $x$, in 1.0 mol/L KOH. Insert in (a) Top-down view of the $\mathrm{Fe}_{2} \mathrm{P}$ (002) surface [89]. (C) 2017 American Chemical Society; (c) Polarization curves of Ni $2 \mathrm{P}$ NSAs/NF, Ni ${ }_{1.85} \mathrm{Fe}_{0.15} \mathrm{P}$ NSAs/NF, $\mathrm{IrO}_{2}$ on NF, and bare NF in $1.0 \mathrm{~mol} / \mathrm{L} \mathrm{KOH}$ with a scan rate of $5 \mathrm{mV} \mathrm{s}{ }^{-1}$ [92]. (C) 2017 American Chemical Society; (d) Side view of the Al-CoP(101) surface with one $\mathrm{Al}$ atom replacing the second-layer Co atom (green ball represents the doped $\mathrm{Al}$ atom). (e) DOS of Co atoms on the pristine CoP(101) and $\mathrm{CoP}(101)$ surface with $8.3 \% \mathrm{Al}$ doped on the second-layer. (f) OER polarization curves for Al-CoP/CC, CoP/CC, CC and RuO2 [87]. C The Royal Society of Chemistry 2017; (g) Schematic illustration of hollow Fe-Co-P alloy material synthesis. (h) OER polarization curves for the Fe-Co-P alloy, CoP $\mathrm{FeP}$, and $\mathrm{CoFe}_{2} \mathrm{O}_{4}$ nanostructures [96]. 2017 American Chemical Society.

action. Anions doping is also accessible for controlling the surface states of electrocatalysts [98-104]. Hu's group [101] found that $\mathrm{Ni}_{2} \mathrm{P}$ nanoparticles are Janus catalysts for water splitting in $1 \mathrm{~mol} / \mathrm{L} \mathrm{KOH}$, and this high activity was attributed to the core-shell $\left(\mathrm{Ni}_{2} \mathrm{P} / \mathrm{NiO}_{x}\right)$ structure. Further, $\mathrm{Li}$ and co-workers [98] showed this by adopting phosphorization of $\mathrm{Ni}(\mathrm{OH})_{2}$. This hydroxyl incorporation $\mathrm{Ni}_{2} \mathrm{P}$ exhibited superior activity than pure $\mathrm{Ni}_{2} \mathrm{P}$ (Fig. 5). Similar observation were reported for $\mathrm{CoP}$ [102], $\mathrm{Co}_{2} \mathrm{P}$ [103] and even bimetal phosphides such as MnCoP [99] and $\mathrm{Co}_{3} \mathrm{FeP}$ [100]. For example, Guan et al. [99] synthesized highly complex multishell mixed-metal oxyphosphide particles for OER. Following an activation process at a constant potential, the multishell Mn-Co oxyphosphide particles exhibit enhanced electrocatalytic activity in the oxygen evolution reaction and outstanding durability. The incorporation of $\mathrm{Mn}^{2+}$ cat- ions and $\mathrm{O}^{2-}$ anions into the cobalt phosphide could result in the increased conductivity and the formation of new active sites, which are important for enhanced electrochemical activity and stability in the OER. In sum, surface modification of metal phosphides by anion incorporation is another way to improve their catalytic performances.

\subsection{Metal sulfides}

Compared to metal phosphides, metal sulfides have equally emerged as a prominent class of materials for OER. Actually, the two kinds of materials have many similarities in physical-chemical properties. For instance, the bonding scheme of metal phosphides and metal sulfides are semblable: most of them share metal-metalloid bonds (M-P or M-S) with a strong 

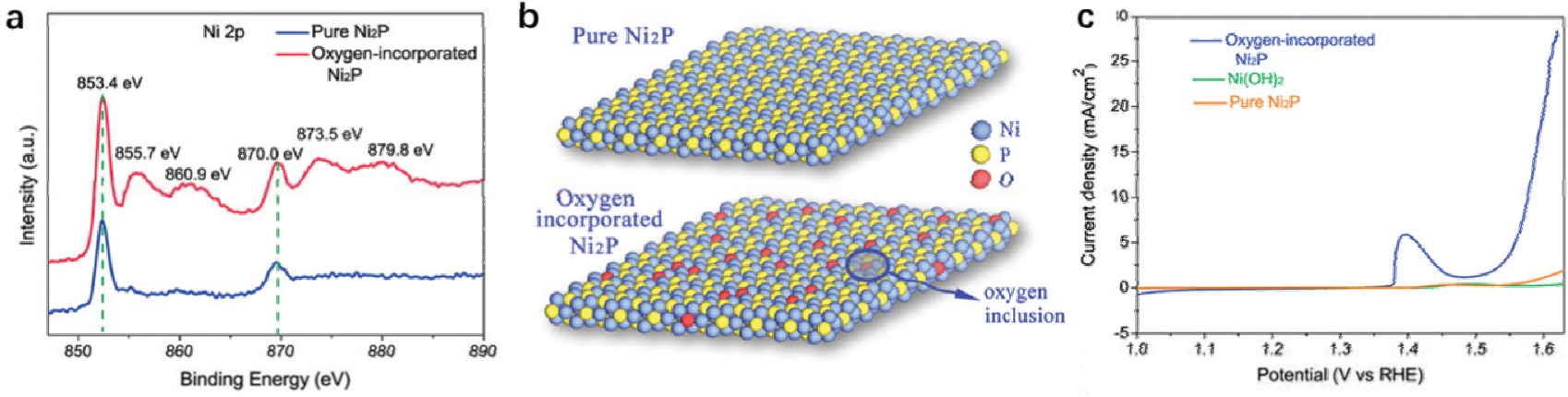

Fig. 5. (a) High resolution XPS spectra of $\mathrm{Ni} 2 p$ core level of the obtained oxygen-incorporated $\mathrm{Ni}_{2} \mathrm{P}$ nanosheets and the pure $\mathrm{Ni}_{2} \mathrm{P}$. (b) Atomic structure model of the pure $\mathrm{Ni}_{2} \mathrm{P}$ and obtained oxygen-incorporated $\mathrm{Ni}_{2} \mathrm{P}$ nanosheets. (c) Polarization curves of oxygen-incorporated $\mathrm{Ni}_{2} \mathrm{P}$ nanosheets, $\mathrm{Ni}(\mathrm{OH})_{2}$ precursor and pure $\mathrm{Ni}_{2} \mathrm{P}$ samples as the electrocatalyst [98]. (C) the Partner Organisations 2016.

covalent component, together with strong and highly covalent metalloid-metalloid bonds (P-P or S-S) [39]. Besides, Metal sulfides are a major group of minerals that provide the crystal chemist a rich field for investigation due to their diverse structural types. They are abundant and cheap since they usually exist in nature as minerals such as heazlewoodite $\left(\mathrm{Ni}_{3} \mathrm{~S}_{2}\right)$, chalcocite $\left(\mathrm{Cu}_{2} \mathrm{~S}\right)$, pyrite $\left(\mathrm{FeS}_{2}\right)$ and so on [105]. These specific features provide metal sulfides with unique properties, complemented by a wide range of compositions, crystal structures, and accessible electronic states, which allow us to envision a myriad of novel discoveries. For instance, $\mathrm{CoS}, \mathrm{NiCo}_{2} \mathrm{~S}_{4}, \mathrm{Ni}_{3} \mathrm{~S}_{2}$, $\mathrm{Cu}_{2} \mathrm{ZnSnS}_{4}$, etc., have been introduced in recent years as electrocatalysts for OER with excellent results $[27,28]$. However, to meet the strict requirements of industrial electrolysis devices, improvement in the material part is still required to replace those precious metal-based electrocatalysts. Common pitfalls of these reported electrocatalysts are fewer active sites, poor electrical transport, inefficient electrical contact with the electrolyte, and instability under operating conditions [106].

Nanostructuring metal sulfides have been extensively studied, as when the size of the metal sulfides is reduced to the nanometer scale, new physical and chemical properties emerge owing to the well-known quantum size effect [107]. In addition, nanostructured metal sulfides can provide a much higher specific surface area as compared with their bulk counterparts, which is beneficial to energy devices because the reaction/interaction between the devices and the interacting media can be significantly enhanced [108]. By feat of the progress in the synthesis technique, various metal sulfide nanostructure arrays have been synthesized [27]. For instance, $\mathrm{Wu}$ and coworkers [109] reported the morphology-controllable synthesis of zinc cobalt mixed sulfide (Zn-Co-S) nanoarchitectures, including nanosheet, nanoplate, and nanoneedle, grown on conductive carbon fiber paper (CFP) and the micronanostructure dependent electrochemical efficacy for catalyzing hydrogen and oxygen in zinc-air batteries and water splitting. The formation of different Zn-Co-S morphologies was attributed to the synergistic effect of decomposed urea products and the corrosion of $\mathrm{NH}_{4} \mathrm{~F}$. Among synthesized $\mathrm{Zn}$-Co-S nanostructures, the nanoneedle arrays supported on CFP exhibit superior trifunctional activity for oxygen reduction, oxygen evolution, and hydrogen evolution reactions than its nanosheet and nanoplate counterparts through half reaction testing. The superior performance is contributed to the integrated nanoneedle/CFP nanostructure, which not only provides enhanced electrochemical active area, but also facilitates ion and gas transfer between the catalyst surface and electrolyte, thus maintaining an effective solid-liquid-gas interface necessary for electroca-

Table 1

Benchmarking the metal phosphide based electrocatalysts with respect to the OER overpotential at $10 \mathrm{~mA} \mathrm{~cm}^{-2}\left(\eta^{10}\right)$.

\begin{tabular}{|c|c|c|c|c|c|}
\hline No. & Catalyst & Electrolyte & $\begin{array}{c}\eta^{10} \\
(\mathrm{mV})\end{array}$ & $\begin{array}{c}\text { Tafel } \\
\text { slope } \\
(\mathrm{mV} / \mathrm{dec})\end{array}$ & Ref. \\
\hline$\overline{1}$ & CoP hollow polyhedron & $1 \mathrm{~mol} / \mathrm{L} \mathrm{KOH}$ & 400 & 57.0 & [46] \\
\hline 2 & Co-P foam & $1 \mathrm{~mol} / \mathrm{L} \mathrm{KOH}$ & 300 & 74.0 & [51] \\
\hline 3 & Flower-like NiFe-P & $1 \mathrm{~mol} / \mathrm{L} \mathrm{KOH}$ & 233 & 42.5 & [52] \\
\hline 4 & CoP-based nanoneedle & $1 \mathrm{~mol} / \mathrm{L} \mathrm{KOH}$ & 281 & - & [53] \\
\hline 5 & CoP NWs & $1 \mathrm{~mol} / \mathrm{L} \mathrm{KOH}$ & 248 & 78.0 & [54] \\
\hline 6 & $\mathrm{Co}_{2} \mathrm{P}$ NWs & $1 \mathrm{~mol} / \mathrm{L} \mathrm{KOH}$ & $\sim 270$ & 62.0 & [70] \\
\hline 7 & CoP-MNA & $1 \mathrm{~mol} / \mathrm{L} \mathrm{KOH}$ & 290 & 65.0 & [71] \\
\hline 8 & $\left(\mathrm{Ni}_{0.5} \mathrm{Fe}_{0.5}\right)_{2} \mathrm{P}$ microflower & $1 \mathrm{~mol} / \mathrm{L} \mathrm{KOH}$ & 203 & 57.0 & [72] \\
\hline 9 & CP@Ni-P & $1 \mathrm{~mol} / \mathrm{L} \mathrm{KOH}$ & $\sim 270$ & 73.0 & [73] \\
\hline 10 & CoP-CNT & $\begin{array}{l}0.1 \mathrm{~mol} / \mathrm{L} \\
\mathrm{NaOH}\end{array}$ & 330 & 50.0 & [74] \\
\hline 11 & $\mathrm{Co}_{2} \mathrm{P} / \mathrm{Co}$-foil & $1 \mathrm{~mol} / \mathrm{L} \mathrm{KOH}$ & 319 & 79.0 & [77] \\
\hline 12 & Co-Pi NA/Ti & $0.1 \mathrm{~mol} / \mathrm{L} \mathrm{PBS}$ & 450 & 187.0 & [78] \\
\hline 13 & $\mathrm{Cu}_{3} \mathrm{P} / \mathrm{CF}$ & $0.1 \mathrm{~mol} / \mathrm{L} \mathrm{KOH}$ & $412 @ 50$ & 63.0 & [79] \\
\hline 14 & FeP@CNT & $1 \mathrm{~mol} / \mathrm{L} \mathrm{KOH}$ & 300 & 53.0 & [84] \\
\hline 15 & $\mathrm{NiCoP} / \mathrm{rGO}$ & $1 \mathrm{~mol} / \mathrm{L} \mathrm{KOH}$ & 270 & 65.7 & [85] \\
\hline 16 & $\mathrm{Fe}_{1.1} \mathrm{Mn}_{0.9} \mathrm{P}$ nanorod & $1 \mathrm{~mol} / \mathrm{L} \mathrm{KOH}$ & 440 & 39.0 & [89] \\
\hline 17 & $\mathrm{Ni}_{1.85} \mathrm{Fe}_{0.15} \mathrm{P}$ NSAs/NF & $1 \mathrm{~mol} / \mathrm{L} \mathrm{KOH}$ & $270 @ 20$ & 96.0 & [92] \\
\hline 18 & $\mathrm{Co}_{0.7} \mathrm{Fe}_{0.3} \mathrm{P} / \mathrm{CNT}$ & $1 \mathrm{~mol} / \mathrm{L} \mathrm{KOH}$ & 243 & 35.0 & [91] \\
\hline 19 & $\mathrm{Co}_{0.68} \mathrm{Fe}_{0.32} \mathrm{P}$ polyhedrons & $1 \mathrm{~mol} / \mathrm{L} \mathrm{KOH}$ & 289 & 66.0 & [95] \\
\hline 20 & $\mathrm{Al}-\mathrm{CoP} / \mathrm{CC}$ & $1 \mathrm{~mol} / \mathrm{L} \mathrm{KOH}$ & 330 & 67.0 & [87] \\
\hline 21 & Fe-Co-P alloy & $1 \mathrm{~mol} / \mathrm{L} \mathrm{KOH}$ & 252 & 33.0 & [96] \\
\hline 22 & $\mathrm{Ni}_{2} \mathrm{P} / \mathrm{NiO}_{x}$ nanoparticles & $1 \mathrm{~mol} / \mathrm{L} \mathrm{KOH}$ & 290 & 59.0 & {$[101]$} \\
\hline 23 & $\begin{array}{c}\text { O-incorporated } \mathrm{Ni}_{2} \mathrm{P} \\
\text { nanosheets }\end{array}$ & $0.1 \mathrm{~mol} / \mathrm{L} \mathrm{KOH}$ & 347 & 63.0 & [98] \\
\hline 24 & CoP NR/C & $1 \mathrm{~mol} / \mathrm{L} \mathrm{KOH}$ & 320 & 71.0 & {$[102]$} \\
\hline 25 & Needle-shaped $\mathrm{Co}_{2} \mathrm{P}$ & $1 \mathrm{~mol} / \mathrm{L} \mathrm{KOH}$ & 310 & 50.0 & [103] \\
\hline 26 & $\begin{array}{l}\text { Mn-Co oxyphosphide } \\
\text { particles }\end{array}$ & $1 \mathrm{~mol} / \mathrm{L} \mathrm{KOH}$ & 320 & 52.0 & [99] \\
\hline 27 & $\mathrm{Co}_{3} \mathrm{FeP}_{x} \mathrm{O}$ & $1 \mathrm{~mol} / \mathrm{L} \mathrm{KOH}$ & 291 & 85.0 & {$[100]$} \\
\hline 28 & $\alpha-\mathrm{Co}_{2} \mathrm{P}$ nanoparticles & $0.1 \mathrm{~mol} / \mathrm{L} \mathrm{PBS}$ & 592 & 94.4 & {$[160]$} \\
\hline 29 & $0-\mathrm{Ni}_{1-x} \mathrm{Fe}_{x} \mathrm{P}_{2}(x=0.25)$ & $1 \mathrm{~mol} / \mathrm{L} \mathrm{KOH}$ & 155 & 55.0 & [163] \\
\hline
\end{tabular}


talysis. Besides, there are many researchers studied on metal sulfides with various nanostructures, such as nanosheet structures of NiS [110,111], CuS [112], Co-S [113-115], and FeNiS2 [116], $\mathrm{NiCo}_{2} \mathrm{~S}_{4}$ nanowires [117], $\mathrm{Bi}_{2} \mathrm{~S}_{3}$ nanorod [118], $\mathrm{Co}_{9} \mathrm{~S}_{8}$ hollow spheres $[119,120]$, and so on, almost all of these catalysts exhibit better OER activity than the same component with block nanostructure.

Rationally designing and synthesizing the active sites of OER catalysts is also important to make their overall catalytic performance close to, or even better than, that of noble metals. To achieve this goal, tailoring the size and assembly patterns of nanocatalysts is the most promising route, by which the density of the most active crystallographic facets on the surfaces of various nanomaterials increase, as has recently been demonstrated for various noble metal and metal oxide catalysts [123-125]. It has been demonstrated that, as for spinels, the octahedral sites are catalytically active; while the tetrahedral sites are almost inert [126]. Knözinger et al. [127] reported that the [111] plane of spinel exposes octahedrally coordinated cations solely, suggesting that these facets should be more reactive than other crystal facets. Recently, Liu et al. [121] synthesized high active $\mathrm{Co}_{3} \mathrm{~S}_{4}$ atomically thin nanosheets (CSATN) for OER (Fig. 6(a) and (b)), suggested that high-spin states of $\mathrm{Co}^{3+}$ in octahedral sites also significantly enhance the OER per- formance of spinel catalysts. High-angle annular dark field (HAADF) and temperature-dependent electron paramagnetic resonance (EPR) were applied to explain the difference of valence and spin state of Co between bulk and CSATN. As displayed in Fig. 6(c) and (d), the phenomenon of a shifting of the spectral weight to lower magnetic fields at low temperatures infers the existence of ferromagnetic coupling in CSATN, which concludes all of Co ion with a high-spin state. HAADF images (Fig. 6(e)-(g)) were further used to help visualize that the planes solely expose octahedral coordinated cations and demonstrate that elongation of Jahn-Teller distortions occur. Briefly, strained exfoliated CSATN induces changes in the Co spin states, and the consequent $\mathrm{HS} \mathrm{Co}^{3+}$ in octahedra $\left(t_{2 \mathrm{~g}}{ }^{4} e_{\mathrm{g}}{ }^{2}\right)$ will distort (Jahn-Teller effect) to remove the degeneracy and form a slightly distorted prism (Fig. 3(h)).

However, the catalytically favorable surface atomic structures always exist on high-index facets. Owing to their high surface energy, these facets often evolve and disappear rapidly during the synthesis of the materials or their use in catalysis [128]. Thus, making high-index faceted nanocatalysts with good structural stability is a challenging yet appealing conundrum to solve, toward meeting our goal of making efficient noble-metal-free (electro) catalysts. Further, Chauhan et al. [122] modified an earlier synthesis method by introducing
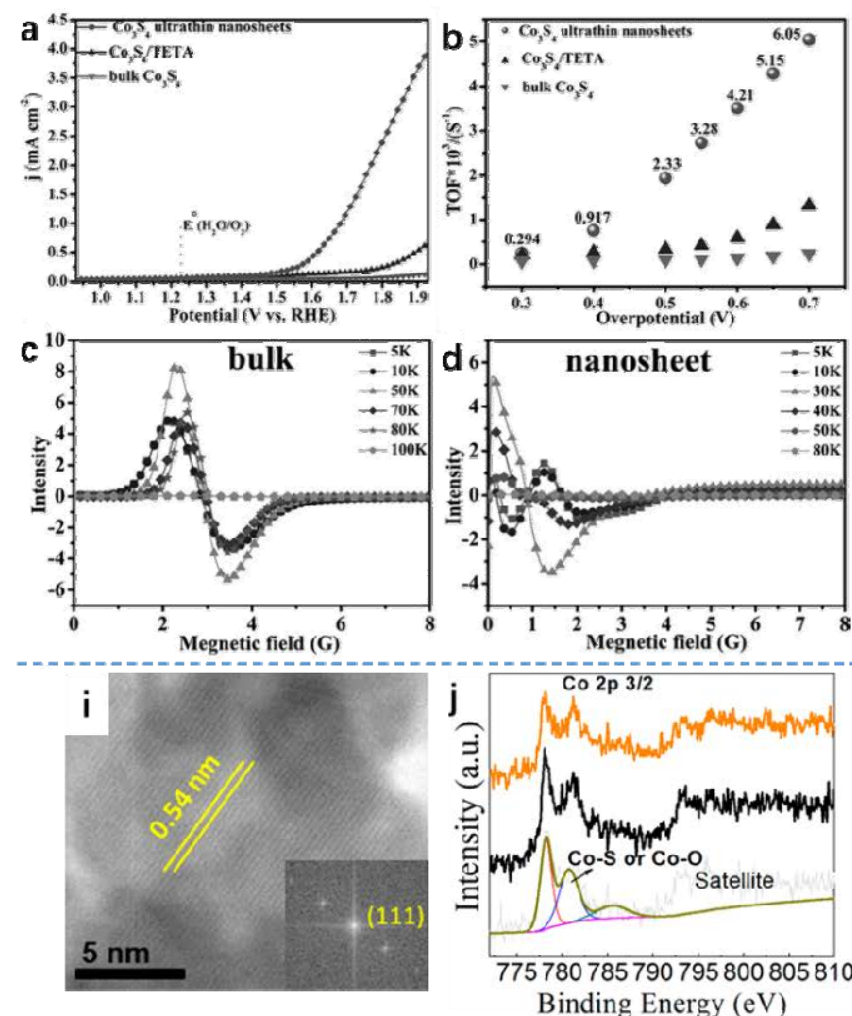
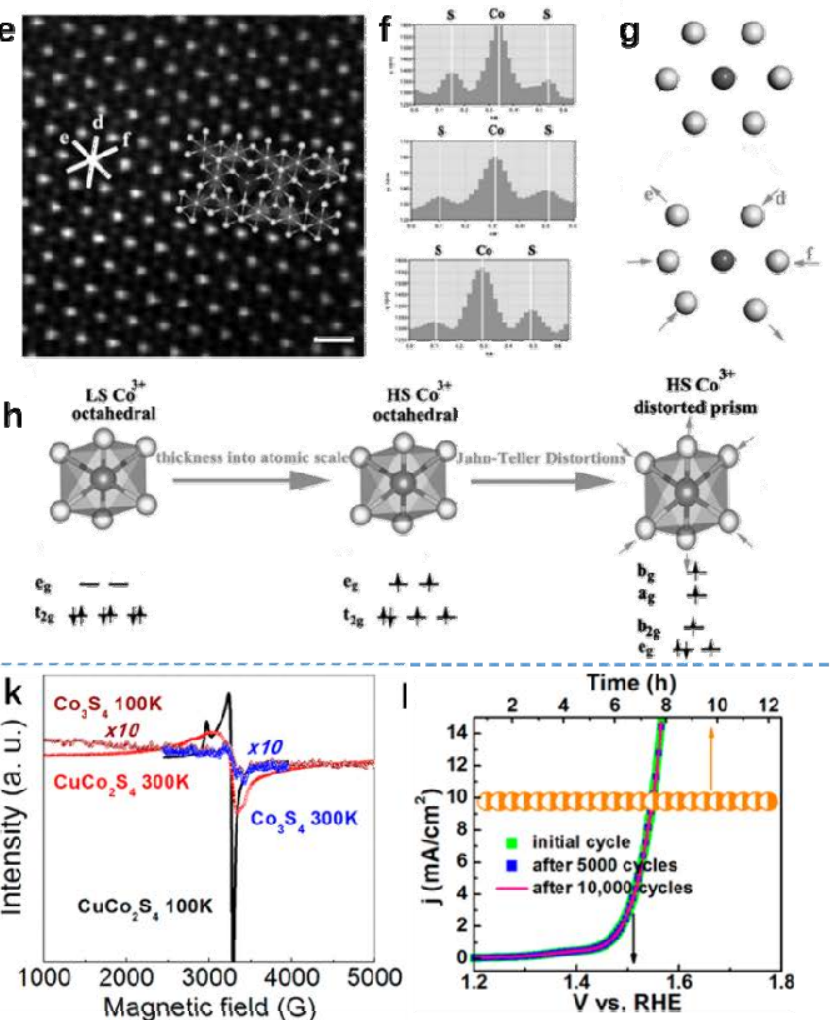

Fig. 6. (a) LSV polarization curves and (b) a plot of TOFs with respect to Co atoms at different overpotentials. (c, d) Temperature-dependent EPR of bulk and CSATN. (e) HAADF images of CSATN and (f) HAADF intensity line profiles along the directions signed by the white lines in (e). (g) [111] zone axis section view of original octahedral and Jahn-Teller distortion. (h) Representations of structural transformation by reducing its thickness to the atomic scale [121]. (C)2015 Wiley-VCH Verlag GmbH \& Co. KGaA, Weinheim. (i) HRTEM image of a CuCo $\mathrm{S}_{4}$ nanosheet lying flat on a TEM grid (inset, calculated FFT pattern). (j) Comparison of high-resolution XPS spectra of all fresh $\mathrm{CuCo}_{2} \mathrm{~S}_{4}, \mathrm{Cu}_{0.5} \mathrm{Co}_{2.5} \mathrm{~S}_{4}$, and $\mathrm{Co}_{3} \mathrm{~S}_{4}$ nanosheet samples. (k) Temperature-dependent EPR spectra of $\mathrm{CuCo}_{2} \mathrm{~S}_{4}$ and $\mathrm{Co}_{3} \mathrm{~S}_{4}$ nanosheets. (l) LSV curves of a single $\mathrm{CuCo}_{2} \mathrm{~S}_{4}$ working electrode after the first cycle and after 5000 and 10000 cycles and chronoamperometric curves obtained with a constant current $\left(j=10 \mathrm{~mA} \mathrm{~cm}{ }^{-2}\right)$ during bulk water splitting with a $\mathrm{CuCo}_{2} \mathrm{~S}_{4}$-coated GC electrode in $1 \mathrm{M} \mathrm{KOH}$ solution at $\eta=0.31 \mathrm{~V}$ [122]. (C) 2017 American Chemical Society. 
ethylenediamine as a surfactant to prepare two-dimensional (2D) $\mathrm{CuCo}_{2} \mathrm{~S}_{4}$ nanosheets that are exposed mainly with (111) facets (Fig. 6(i)). By introduction of $\mathrm{Cu}$ into the $\mathrm{Co}_{3} \mathrm{~S}_{4}, \mathrm{CuCo}_{2} \mathrm{~S}_{4}$ with spinel structure generated, in which catalytically active high-spin $\mathrm{Co}^{3+}$ ions tend to occupy octahedral B sites and divalent $\mathrm{Cu}^{2+}$ ions occupy the tetrahedral A site. The presence of high-spin $\mathrm{Co}^{3+}$ at the particle surface as well as the replacement of $\mathrm{Co}^{2+}$ with $\mathrm{Cu}^{2+}$ in the crystal lattice were evidenced by XPS and EPR, as shown in Fig. 6(j) and (k). When used as an electrocatalyst, $\mathrm{CuCo}_{2} \mathrm{~S}_{4}$ nanosheets showed a high OER activity and stability, i.e., an overpotential value of $310 \mathrm{mV}$ at a $10 \mathrm{~mA}$ $\mathrm{cm}^{-2}$ current density, and remained consistent for 10000 measured cycles in a $1 \mathrm{~mol} / \mathrm{L} \mathrm{KOH}$ electrolyte (Fig. 6(l)).

As described before, metal sulfides have a rich crystal chemist for investigation. The diverse structural types of metal sulfides are attributed to the factors that sulfur element has six outer electrons and the electronegativity is moderate. For example, nickel sulfides, have various phases, such as $\mathrm{NiS}, \mathrm{NiS}_{2}$, $\mathrm{Ni}_{3} \mathrm{~S}_{2}, \mathrm{Ni}_{7} \mathrm{~S}_{6}$ and $\mathrm{Ni}_{9} \mathrm{~S}_{8}$ [6], wherein, $\mathrm{NiS}$ and $\mathrm{NiS}_{2}$ have been widely studied for lithium-ion batteries [130], supercapacitors [131], dye-sensitized solar cells [132,133] and hydrodesulphurization catalysts [134]. It has been reported that the sulfides with different phases exhibit special catalytic activity for various electrochemical reactions [129,135-140]. NiS 2 has two main phases; especially, the cubic phase shows a better catalytic performance than the triclinic phase in HER [141]. Compared with $\mathrm{NiS}_{2}$, NiS is more suitable for OER [142]. This phenomenon inspires researchers to selectively synthesize metal sulfides in its high-active phase as OER catalysts. Luo et al. [136] reported a precise heat control strategy to convert the
$\mathrm{NiS}_{2}$ into NiS phase, obtaining an OER catalyst with high activity and good stabilization. Yang and coworkers [140] systematically studied the chemical valence-dependent electrocatalytic activities of nickel sulfides with different oxidation state of $\mathrm{Ni}$ from $\mathrm{Ni}_{9} \mathrm{~S}_{8}$, to $\mathrm{Ni}_{9} \mathrm{~S}_{8}-\mathrm{NiS}_{1.03}$ alloy and $\mathrm{NiS}_{1.03}$ by controlling the sulfidation process. The OER electrocatalytic activities gradually enhanced with the increase of high-valence Ni component. Apart from the nickel sulfides, the phase and composition of cobalt sulfide $\left(\operatorname{CoS}_{x}\right)$ greatly affect their electrocatalytic performances for OER. Very recently, Ma et al. [129] reported three $\mathrm{CoS}_{x}$ compounds, i.e., $\mathrm{Co}_{9} \mathrm{~S}_{8}, \mathrm{Co}_{3} \mathrm{~S}_{4}$, and $\mathrm{CoS}_{2}$ hollow nanospheres (HNSs) and studied their catalytic efficiencies for hydrogen and oxygen evolution reactions in alkaline media (Fig. 7(a) and (b)). The three $\mathrm{CoS}_{x}$ HNSs were precisely synthesized by simply adjusting the molar ratio of carbon disulfide to cobalt acetate using a facile solution-based strategy. As shown in Fig. 7(c) and (d), electrochemical results reveal that the as-prepared $\mathrm{CoS}_{2} \mathrm{HNSs}$ exhibit superior OER and HER catalytic performance to $\mathrm{Co}_{9} \mathrm{~S}_{8}$ and $\mathrm{Co}_{3} \mathrm{~S}_{4}$ HNSs in $1.0 \mathrm{~mol} / \mathrm{L} \mathrm{KOH}$, with overpotentials of $290 \mathrm{mV}$ for the OER and $193 \mathrm{mV}$ for the HER at $10 \mathrm{~mA} \mathrm{~cm}^{-2}$, and the corresponding Tafel slopes of 57 and

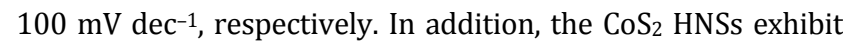
remarkable long-term catalytic durability, which is even superior to precious metal catalysts of $\mathrm{RuO}_{2}$ and Pt/C. Further analysis revealed a greater amount of $\mathrm{CoS}_{6}$ octahedra leads to the superior intrinsic OER activity (Fig. 7(e)).

For metal sulfide-based electrocatalyst, it is noteworthy that the catalytic active sites locate at metal sites. The preceding discussion suggests that catalytic efficiency of metal-based catalyst is highly influenced by the microchemical environmental
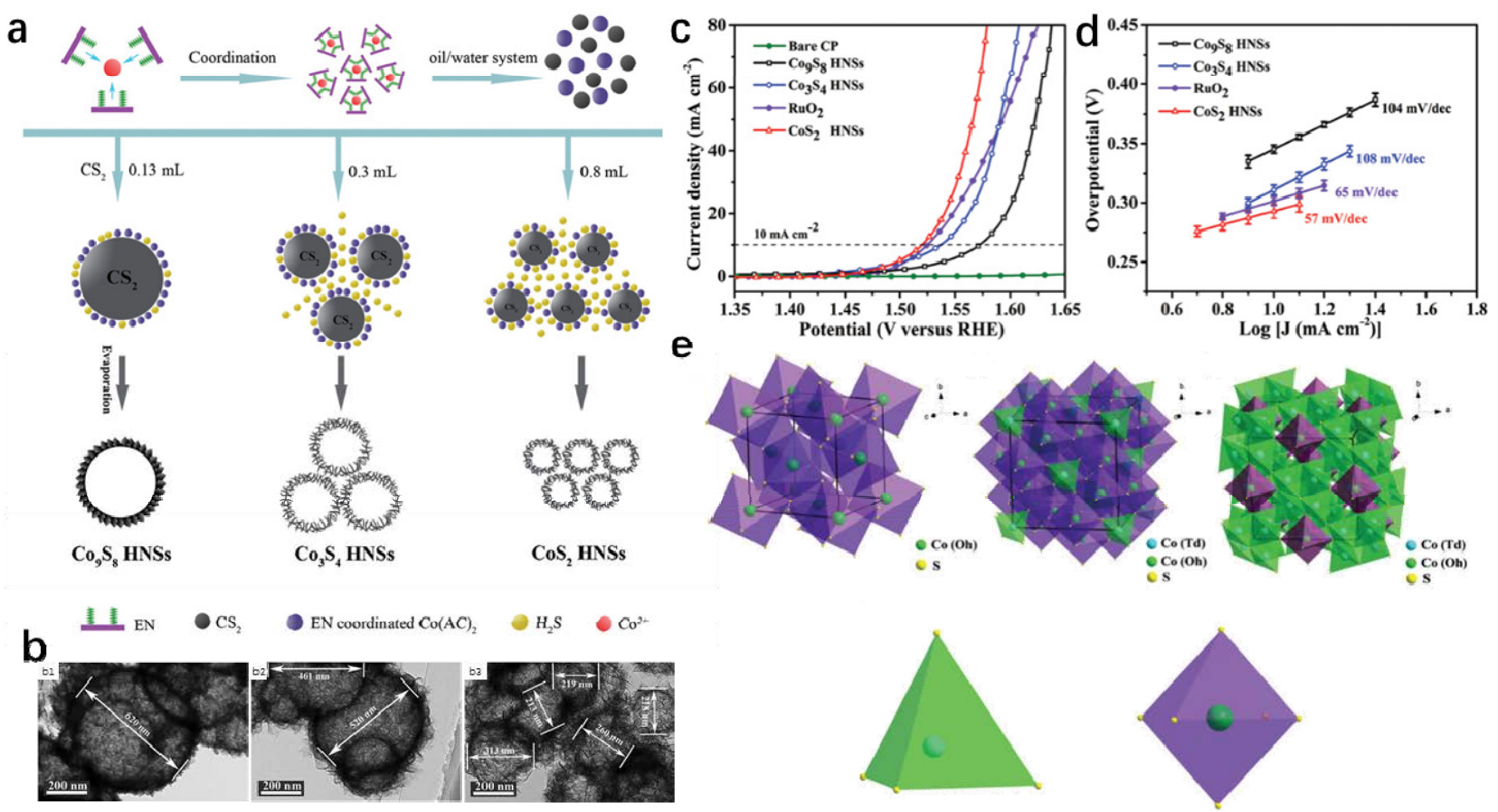

inn

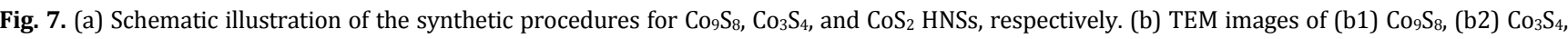

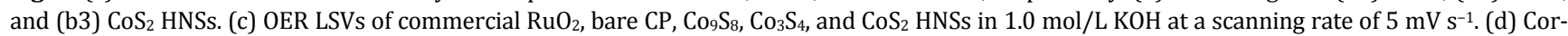
responding Tafel curves. Error bars represent standard deviations from three independent repeated measurements. (e) $\mathrm{Crystal}_{\mathrm{s}}$ structures of (a) CoS ${ }_{2}$, (b) $\mathrm{Co}_{3} \mathrm{~S}_{4}$, (c) $\mathrm{Co}_{9} \mathrm{~S}_{8}$, (d) $\mathrm{CoS}_{4}$ tetrahedron and (e) $\mathrm{CoS}_{6}$ octahedron, respectively [129]. (c) The Royal Society of Chemistry 2018. 
of metal sites. The activity of metal centers would be enhanced by introducing doping ions due to the synergetic chemical coupling effects between them [143-147]. In 2015, Cheng et al. [145] described their finding that the Fe-doped $\mathrm{Ni}_{3} \mathrm{~S}_{2}$ particle film in situ hydrothermally grown on NF with $11.8 \%$ Fe-content $\left(\mathrm{Fe}_{11.8 \%}-\mathrm{Ni}_{3} \mathrm{~S}_{2} / \mathrm{NF}\right)$ behaves as a cost-effective OER electrode excellent in activity and stability in strongly alkaline electrolytes. Very recently, Hui et al. [147] presented a facile and universal strategy for fabricating dual metal sulfides (Fe$\mathrm{CoS}$ ) by controlling the atomic ratio of metal precursors for water splitting in basic media. Combining experimental results with DFT calculations, they found that the elaborate modulation of metal ratios could effectively improve the catalytic activity. Li et al. [143] demonstrated that metal doping could modify the electronic structure of the electrocatalytically active center of electrocatalysts. Co-doped $\mathrm{Cu}_{7} \mathrm{~S}_{4}$ nanodisks were synthesized and investigated as highly efficient electrocatalyst for OER due to the optimized electronic structure of the active centers. As shown in Fig. 8(a)-(c), DFT calculations revealed that Co-engineered $\mathrm{Cu}_{7} \mathrm{~S}_{4}$ could accelerate electron transfer between $\mathrm{Co}$ and $\mathrm{Cu}$ sites, thus decrease the energy barriers of intermediates and products during OER, which are crucial for enhanced catalytic properties. As expected, Co-engineered $\mathrm{Cu}_{7} \mathrm{~S}_{4}$ nanodisks exhibited a low overpotential of $270 \mathrm{mV}$ to achieve current density of $10 \mathrm{~mA} \mathrm{~cm}-2$ as well as decreased Tafel slope and enhanced turnover frequencies as compared to bare $\mathrm{Cu}_{7} \mathrm{~S}_{4}$ (Fig. 8(e) and (f)). Meanwhile, the electronic structure reconfiguration of pyrite $\mathrm{NiS}_{2}$ was observed from typical semi-conductive characteristics to metallic characteristics by engineering vanadium (V) displacement defect (Fig. 8(g) and (h)), which was confirmed by both experimental temperature-dependent resistivity and theoretical density functional theory calculations [144]. Furthermore, X-ray absorption spectroscopy measurements and DFT calculations (Fig. 8(i)-(k)) revealed that electronic structure reconfiguration of $\mathrm{NiS}_{2}$ is rooted in electron transfer from doped $\mathrm{V}$ to $\mathrm{Ni}$ sites, consequently enabling $\mathrm{Ni}$ sites to gain more electrons. This work provides insights into electronic structure engineering from well-designed atomic defect metal sulfide.

There are also many researches focused on anions doping to control the chemical and physical properties of electrocatalysts. Sultana et al. [150] created an amorphous $\mathrm{CoS}_{x}$ film containing oxygen, which was active for the OER in alkaline conditions with evidence of conversion to cobalt oxide. Cai et al. [148] also prepared an oxygen incorporated amorphous cobalt sulfide porous nanocubes (A-CoS $4.6 \mathrm{O}_{0.6} \mathrm{PNCs}$ ), which was implemented by ion exchange reaction on Prussian Blue Analogue (PBA) with $\mathrm{S}^{2-}$ replacing $\mathrm{Fe}(\mathrm{CN})_{6}{ }^{3-}$. As shown in Fig. 9(a) and (b), A-CoS4.6 $\mathrm{O}_{0.6}$ PNCs owned advantages over the benchmark $\mathrm{RuO}_{2}$ catalyst for catalyzing OER in alkaline/neutral medium. The anionic exchange reaction endows the $\mathrm{A}-\mathrm{CoS}_{4.6} \mathrm{O}_{0.6}$ PNCs with porous structure consisting of a large amount of defective sites. Moreover, the $\mathrm{A}-\mathrm{CoS}_{4.6} \mathrm{O}_{0.6}$ PNCs tend to generate more active Co-S dangling bond with introducing oxygen into host, dramatically strengthening the $\mathrm{O}^{*}$ adsorption that can promote water oxidation reaction with high activity (Fig. 9(c)-(f)). Except for
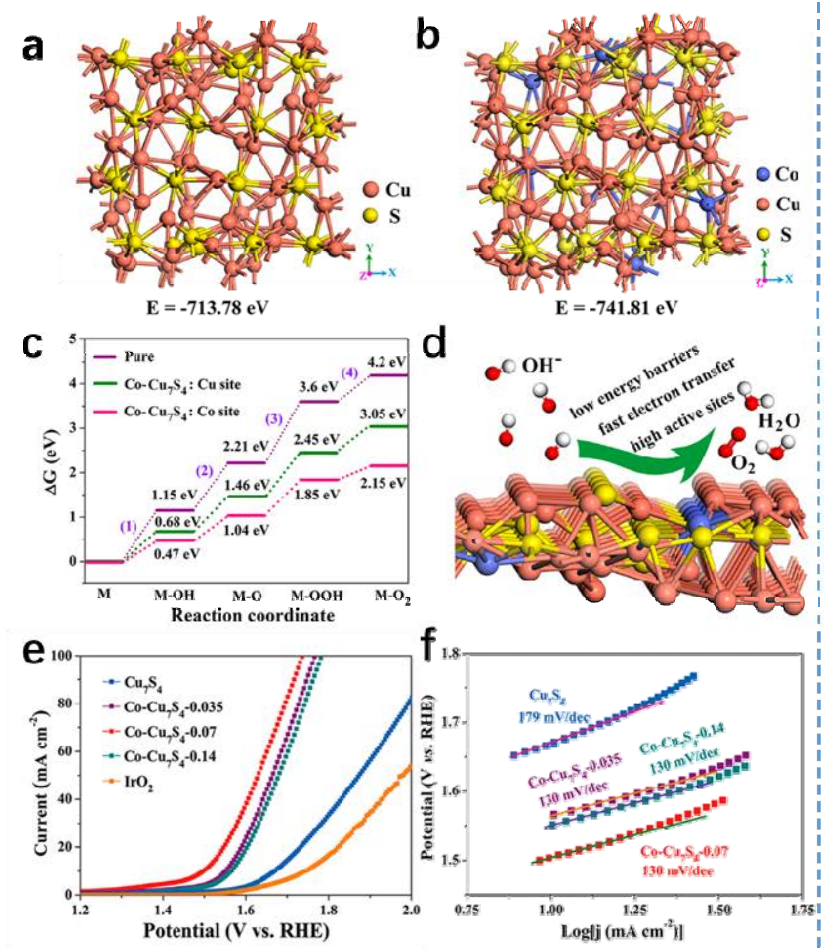

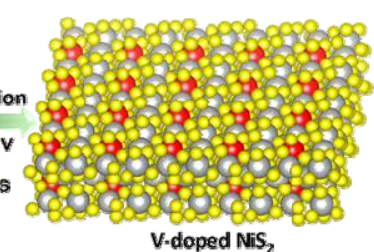

V-doped $\mathrm{NiS}_{2}$
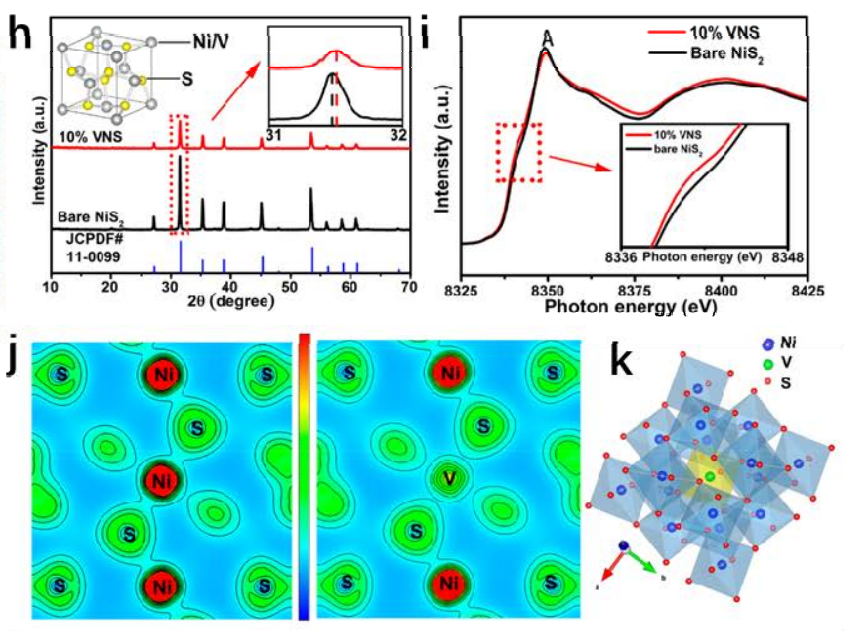

Fig. 8. Crystal structure of (a) $\mathrm{Cu}_{7} \mathrm{~S}_{4}$ and (b) Co-doped $\mathrm{Cu}_{7} \mathrm{~S}_{4}$ (Cu atoms were randomly replaced with Co atoms). (c) Gibbs free energy landscape. (d) The schematic illustrating the feasible OER mechanism for the Co-engineered $\mathrm{Cu}_{7} \mathrm{~S}_{4}$. (e) Polarization curves and (f) Tafel plots of Cu $7 \mathrm{~S}_{4}$ and $\mathrm{Co}_{0}-\mathrm{Cu}_{7} \mathrm{~S}_{4}$ with different Co-doping amounts in $1.0 \mathrm{~mol} / \mathrm{L} \mathrm{KOH} \mathrm{[143].} \mathrm{(C)} 2017$ American Chemical Society. (g) Schematic illustration of the synthesis process for V-doped $\mathrm{NiS}_{2}$. (h) PXRD patterns of bare $\mathrm{NiS}_{2}$ and $10 \%$ VNS (inset: zoomed in view of XRD patterns). (i) Ni K-edge XANES of bare NiS ${ }_{2}$ and $10 \%$ VNS (inset: zoomed-in view of the Ni K-edge XANES). (j) Charge-density contour map for bare $\mathrm{NiS}_{2}$ and $10 \%$ VNS. (k) Crystal structure of $10 \%$ VNS. [144] (C) 2017 American Chemical Society. 

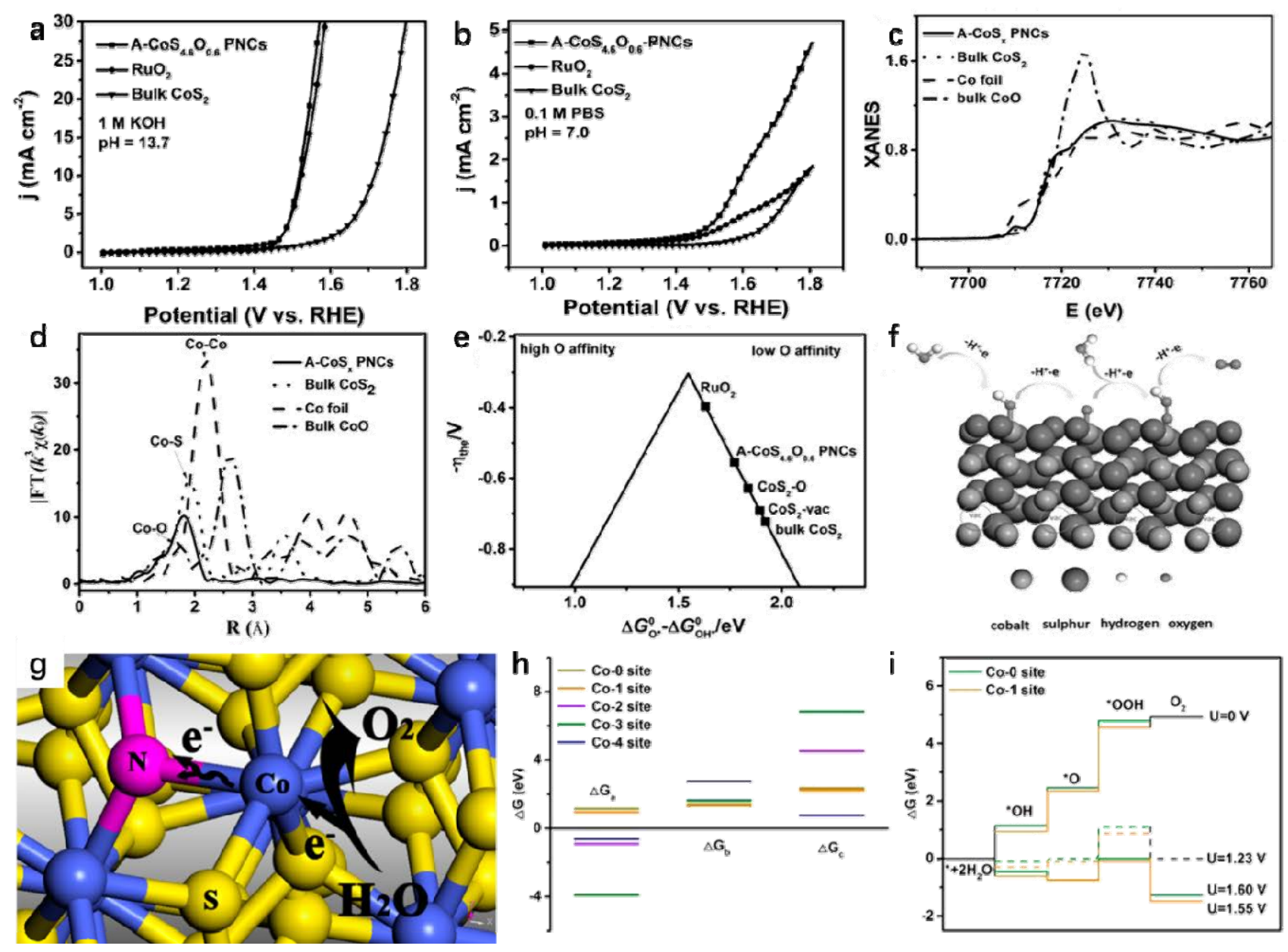

Fig. 9. Polarization curves for OER in $1 \mathrm{~mol} / \mathrm{L} \mathrm{KOH} \mathrm{(pH} \mathrm{13.7)} \mathrm{(a)} \mathrm{and} 0.1 \mathrm{~mol} / \mathrm{L} \mathrm{PBS}$ (pH 7.0) (b) of A-CoS $\mathrm{C}_{4.6} \mathrm{O}_{0.6} \mathrm{PNCs}_{\text {, }} \mathrm{RuO}_{2}$, and bulk CoS . (c) XANES spectra and (d) the corresponding FT curves of A-CoS $4.6 \mathrm{O}_{0.6}$ PNCs, bulk $\mathrm{CoS}_{2}$, Co foil, and bulk CoO. (e) The theoretical volcano plots containing each $\mathrm{CoS}_{2}$ (001) surface. (f) The OER process occurred on the surface of A-CoS $4.6 \mathrm{O}_{0.6}$ PNCs [148]. (C) 2017 Wiley-VCH Verlag GmbH \& Co. KGaA, Weinheim; (g) The schematic illustrating the feasible OER mechanism for the N-doped $\mathrm{CuS}_{2}$. (h) Free energy profiles of different sites. (i) Free-energy diagram for the four steps of the OER at the different applied potentials [149]. (c) 2017 American Chemical Society.

oxygen doping, nitrogen and phosphorus doping have been demonstrated efficient for enhancing the catalytic activity of metal sulfides. Jin et al. [151] reported two different one-step methods to develop nitrogen-decorated iron-nickel sulfides, and both which exhibit an ultra-low overpotential for OER in alkaline solution. To obtain a thorough understanding of the effect of $\mathrm{N}$ doping on the oxygen evolution reaction, Hao et al. [149] experimented with N-doped $\mathrm{CoS}_{2}$ to explore the composition and electronic configurations and their correlations with the electrochemical performance (Fig. 9(g)). Possible active sites for the OER were investigated by DFT calculations (Fig. 9(h) and (i)), which indicate the $\mathrm{N}$ doping is beneficial for excitation of the adjacent Co atoms, forming well-defined electronic configurations, reducing $\Delta G$ of the rate-limiting step and the adsorption of intermediates. Different from N-doping, phosphorus doped metal sulfides were always functioning as bifunctional catalysts for overall water splitting. For example, Dai et al. [152] synthesized a nonstoichiometric pyrrhotite-type cobalt monophosphosulfide material $\left(\mathrm{Co}_{0.9} \mathrm{~S}_{0.58} \mathrm{P}_{0.42}\right)$ with a hexagonal close-packed phase via a partial sulfurization/phosphorization strategy. The synergy between the non- stoichiometric nature and the tunable $\mathrm{P} / \mathrm{S}$ ratio results in the strengthened $\mathrm{Co}^{3+} / \mathrm{Co}^{2+}$ couples and tunable electronic structure and thus efficiently promotes the OER/HER processes toward overall water splitting. Meanwhile, a phosphorus-incorporated cobalt molybdenum sulfide (P-CoMoS) nanocomposites anchored on carbon cloth was fabricated via a two-step synthesis protocol [153], i.e., (1) controllable growth of cobalt molybdenum sulfide (CoMoS) nanocomposites on carbon cloth by a facile hydrothermal method and (2) phosphorization to replace some sulfur atoms with phosphorus atoms. Recently, Zhang et al. [154] further reported a hydrothermal method to dope the P element into Co-Ni-S/NF, which is more environmental friendly as avoided the generation of toxic $\mathrm{PH}_{3}$ gas.

\subsection{Active components of metal phosphide and sulfide}

From the point of view of solid-state chemistry, metal sulfides are thermodynamically less stable than metal oxides under oxidizing potentials and metal phosphides are less stable than sulfides and so forth. Therefore, we can expect that metal 
Table 2

Benchmarking the metal sulfide based electrocatalysts with respect to the OER overpotential at $10 \mathrm{~mA} / \mathrm{cm}^{2}\left(\eta^{10}\right)$.

\begin{tabular}{|c|c|c|c|c|c|}
\hline No. & Catalyst & Electrolyte & $\eta^{10}(\mathrm{mV})$ & $\begin{array}{c}\text { Tafel } \\
\text { slope } \\
(\mathrm{mV} / \mathrm{dec})\end{array}$ & Ref. \\
\hline 1 & Zn-Co-S NN/CFP & $1 \mathrm{~mol} / \mathrm{L} \mathrm{KOH}$ & 320 & 55.0 & [109] \\
\hline 2 & NiS@SLS & $0.1 \mathrm{~mol} / \mathrm{L} \mathrm{KOH}$ & 297 & 47.0 & [110] \\
\hline 3 & $\mathrm{NiS} / \mathrm{NF}$ & $1 \mathrm{~mol} / \mathrm{L} \mathrm{KOH}$ & $320 @ 20$ & 71.0 & [111] \\
\hline 4 & Hydrophilic $\mathrm{Co}_{3} \mathrm{~S}_{4}$ & $1 \mathrm{~mol} / \mathrm{L} \mathrm{KOH}$ & 260 & 84.7 & [113] \\
\hline 5 & $\mathrm{CP} / \mathrm{CTs} / \mathrm{Co}-\mathrm{S}$ & $1 \mathrm{~mol} / \mathrm{L} \mathrm{KOH}$ & 306 & 72.0 & {$[114]$} \\
\hline 6 & Co-S/Ti mesh & $1 \mathrm{~mol} / \mathrm{L} \mathrm{KOH}$ & 361 & 64.0 & [115] \\
\hline 7 & $\mathrm{FeNiS}_{2} \mathrm{NSs}$ & $0.1 \mathrm{~mol} / \mathrm{L} \mathrm{KOH}$ & 310 & 46.0 & [116] \\
\hline 8 & $\mathrm{NiCo}_{2} \mathrm{~S}_{4} \mathrm{NW} / \mathrm{NF}$ & $1 \mathrm{~mol} / \mathrm{L} \mathrm{KOH}$ & 260 & 40.1 & [117] \\
\hline 9 & $\mathrm{Co}_{9} \mathrm{~S}_{8}$ hollow spheres & $1 \mathrm{~mol} / \mathrm{L} \mathrm{KOH}$ & 285 & 58.0 & [119] \\
\hline 10 & $\mathrm{Co}_{9} \mathrm{~S}_{8} \mathrm{HMs}$ & $1 \mathrm{~mol} / \mathrm{L} \mathrm{KOH}$ & 420 & 113.0 & [120] \\
\hline 11 & $\mathrm{CuCo}_{2} \mathrm{~S}_{4}$ nanosheets & $1 \mathrm{~mol} / \mathrm{L} \mathrm{KOH}$ & 310 & 86.0 & [122] \\
\hline 12 & $\mathrm{CoS}_{2} \mathrm{HNSs}$ & $1 \mathrm{~mol} / \mathrm{L} \mathrm{KOH}$ & 290 & 57.0 & [129] \\
\hline 13 & $\begin{array}{l}\text { NiS porous hollow } \\
\text { microspheres }\end{array}$ & $1 \mathrm{~mol} / \mathrm{L} \mathrm{KOH}$ & 320 & 59.0 & [136] \\
\hline 14 & $\mathrm{NiS}_{1.03}-\mathrm{NSCs}$ & $1 \mathrm{~mol} / \mathrm{L} \mathrm{KOH}$ & 270 & 68.9 & {$[140]$} \\
\hline 15 & Co-doped $\mathrm{Cu}_{7} \mathrm{~S}_{4}$ & $1 \mathrm{~mol} / \mathrm{L} \mathrm{KOH}$ & 270 & 130.0 & [143] \\
\hline 16 & V-doped $\mathrm{NiS}_{2}$ & $1 \mathrm{~mol} / \mathrm{L} \mathrm{KOH}$ & 290 & 45.0 & [144] \\
\hline 17 & $\mathrm{Fe}_{11.8 \%}-\mathrm{Ni}_{3} \mathrm{~S}_{2} / \mathrm{NF}$ & $1 \mathrm{~mol} / \mathrm{L} \mathrm{KOH}$ & $257 @ 100$ & 65.5 & [145] \\
\hline 18 & $\mathrm{FeCoS}(\mathrm{Fe} / \mathrm{Co}=1: 0.26)$ & $1 \mathrm{~mol} / \mathrm{L} \mathrm{KOH}$ & 208 & 37.0 & [147] \\
\hline 19 & $\mathrm{~A}-\mathrm{CoS}_{4.6} \mathrm{O}_{0.6} \mathrm{PNCs}$ & $1 \mathrm{~mol} / \mathrm{L} \mathrm{KOH}$ & 290 & 67.0 & [148] \\
\hline 20 & $\mathrm{~N}$-enriched $\mathrm{CoS}_{2}$ & $1 \mathrm{~mol} / \mathrm{L} \mathrm{KOH}$ & 240 & 98.0 & [149] \\
\hline 21 & Oxygen doped $\operatorname{CoS}_{\mathrm{x}}$ & $1 \mathrm{~mol} / \mathrm{L} \mathrm{KOH}$ & 370 & 67.0 & [150] \\
\hline 22 & $\mathrm{~N}-(\mathrm{Ni}, \mathrm{Fe})_{3} \mathrm{~S}_{2} / \mathrm{NIF}$ & $1 \mathrm{~mol} / \mathrm{L} \mathrm{KOH}$ & 167 & 33.0 & [151] \\
\hline 23 & $\mathrm{Co}_{0.9} \mathrm{~S}_{0.58} \mathrm{P}_{0.42}$ & $1 \mathrm{~mol} / \mathrm{L} \mathrm{KOH}$ & 266 & 48.0 & {$[152]$} \\
\hline 24 & P-CoMoS/CC & $1 \mathrm{~mol} / \mathrm{L} \mathrm{KOH}$ & 260 & 72.2 & [153] \\
\hline 25 & P-Co-Ni-S/NF & $1 \mathrm{~mol} / \mathrm{L} \mathrm{KOH}$ & 292 & 61.1 & {$[154]$} \\
\hline 26 & $\begin{array}{c}\text { Ni-Fe disulfide@ } \\
\text { oxyhydroxide }\end{array}$ & $1 \mathrm{~mol} / \mathrm{L} \mathrm{KOH}$ & 230 & 42.6 & {$[161]$} \\
\hline 27 & $\mathrm{NiCo}_{2}(\mathrm{SOH})_{x}$ & $1 \mathrm{~mol} / \mathrm{L} \mathrm{KOH}$ & 290 & 47.0 & [164] \\
\hline
\end{tabular}

sulfides and phosphides would be easily oxidized to the corresponding metal oxides/hydroxides, especially in the aqueous and strongly oxidative environments of OER [155]. In fact, some papers have reported such results and confirmed these points above. In 2015, Hu's group [101] clearly observed several nanometers thick $\mathrm{NiO}_{x}$ shell covered on $\mathrm{Ni}_{2} \mathrm{P}$ nanoparticles by transmission electron microscopy images (Fig. 10(a)), and identified that the "high activity is attributed to the core-shell $\left(\mathrm{Ni}_{2} \mathrm{P} / \mathrm{NiO}_{x}\right)$ structure that the material adopts under catalytic conditions". Meanwhile, Du and co-workers [156] showed that enhancement of the activity in $\mathrm{Ni}_{2} \mathrm{P}$ continued even up to 500 cycles irrespective of the catalyst morphologies (Fig. 10(b) and (c)). With continuous CV scans, the onset potential for water oxidation was decreased and the catalytic current density was enhanced under the same applied potential, indicating that the electroactive species were formed on the electrode surface during CV scans. Interestingly, the original compound was even completely converted into metal oxide/hydroxide in bulk (i.e., not limited to surface oxide) in the case of the conversion of cobalt sulfide and nickel sulfide into their corresponding oxide $[157,158]$. Therefore, the present metal phosphides and sulfides appeared stable for OER might be ascribed to that the conversion to metal oxide/hydroxides either on the surface or in bulk is complete.

The derived metal oxides/hydroxides often display apparent electrocatalytic performance that is better than that of the simple corresponding metal oxides/hydroxides synthesized directly $[80,103]$. Now purposefully used metal chalcogenides/phosphides as the precursors or scaffolds to prepare the oxide/hydroxide OER catalysts on the surface of the original nanostructured materials have been implemented and achieved significantly enhanced catalytic performance using such (nanocomposite) electrocatalysts [159-162]. By using dicobalt phosphide nanoparticles as precatalysts, Xu et al. [160] demonstrated that electrochemical activation of metallic precatalysts in alkaline media (comparing with directly electrochemical activation in neutral media) could significantly promote the OER catalysis in neutral media, specifically realizing a 2-fold enhanced activity and meanwhile showing a greatly decreased overpotential of about $100 \mathrm{mV}$ at $10 \mathrm{~mA} \mathrm{~cm}-2$. Furthermore, a thin crystalline oxyhydroxide layer in situ electrochemically formed on the surfaces of conductive nickel-iron disulfide nanostructures were synthesized by Zhou and coworkers [161]. The crystalline oxyhydroxide layer can effectively prevent the disulfide core from further oxidation, maintains the core-shell structure of the catalyst and is considered to be critical for stable and efficient OER performances.

In fact, these oxidation processes happen inevitably in almost all transition metal catalysts during the OER process, and give rise to the transformation and formation of many new components on the catalysts surface. This fact brings up a
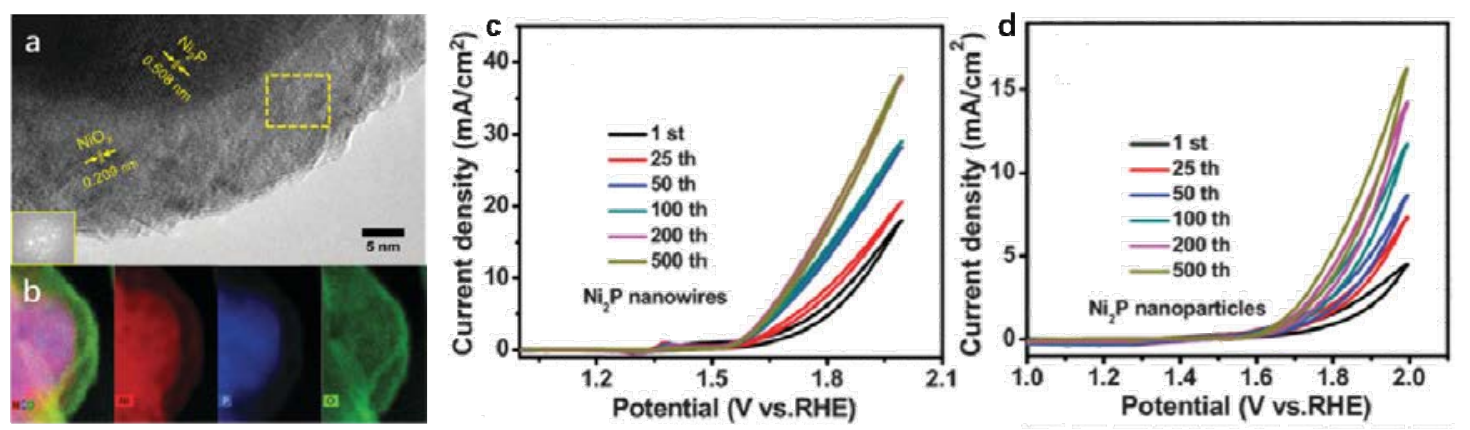

Fig. 10. (a) HRTEM image of the $\mathrm{Ni}_{2} \mathrm{P}$ nanoparticles after electrochemical pretreatment at $1.5 \mathrm{~V}$ vs. RHE for $1 \mathrm{~h}$. Inset (lower left): FFT of the framed area (middle). (b) Corresponding EDX maps of the elements on the sample region shown in (a) [101]. (C2015 The Royal Society of Chemistry; (c) CV scans using the FTO electrode loading $0.1 \mathrm{mg} \mathrm{cm}^{-2} \mathrm{Ni}_{2} \mathrm{P}$ nanowires as the working electrode in $1.0 \mathrm{~mol} / \mathrm{L} \mathrm{KOH} \mathrm{(pH} \mathrm{=13.6).} \mathrm{(d)} \mathrm{CV} \mathrm{scans} \mathrm{using} \mathrm{FTO}$ electrode loading $0.1 \mathrm{mg} \mathrm{cm}^{-2} \mathrm{Ni}_{2} \mathrm{P}$ nanoparticles as the working electrode in $1.0 \mathrm{~mol} / \mathrm{L} \mathrm{KOH} \mathrm{(pH} \mathrm{=} \mathrm{13.6)} \mathrm{[156].} \mathrm{(C2015} \mathrm{The} \mathrm{Royal} \mathrm{Society} \mathrm{of} \mathrm{Chemis-}$ try. 

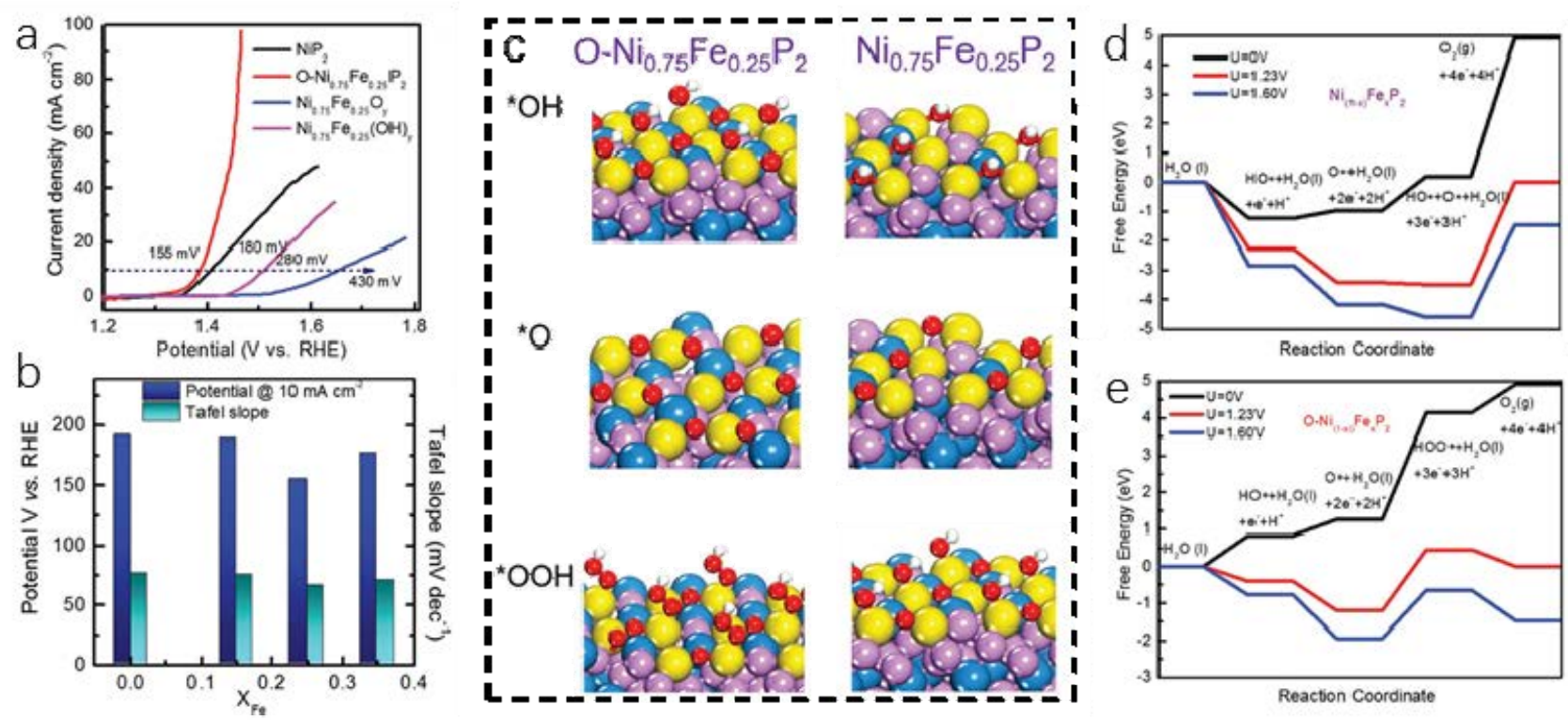

Fig. 11. (a) Polarization curves for $\mathrm{NiP}_{2}, \mathrm{O}_{-} \mathrm{Ni}_{0.75} \mathrm{Fe}_{0.25} \mathrm{P}_{2}, \mathrm{Ni}_{0.75} \mathrm{Fe}_{0.25}(\mathrm{OH})_{y}$ and $\mathrm{Ni}_{0.75} \mathrm{Fe}_{0.25} \mathrm{O}_{y}$ nanosheets in 1.0 mol/L KOH solution. (b) Overpotentials required at $10 \mathrm{~mA} \mathrm{~cm}^{-2}$ and the Tafel slopes for different $\mathrm{O}-\mathrm{Ni}_{1-x} \mathrm{Fe}_{x} \mathrm{P}_{2}$ nanosheets with $x=0,0.15,0.25,0.35$. (c) Atomic confgurations of $\mathrm{OH}, 0$, and $\mathrm{OOH}$ adsorbing $\mathrm{O}-\mathrm{Ni}_{0.75} \mathrm{Fe}_{0.25} \mathrm{P}_{2}(111)$ and $\mathrm{Ni}_{0.75} \mathrm{Fe}_{0.25} \mathrm{P}_{2}$ (111) surface. Free-energy diagram at different potentials for the oxygen evolution reaction on (d) $\mathrm{Ni}_{0.75} \mathrm{Fe}_{0.25} \mathrm{P}_{2}$ (111) and (c) 0-Nio.75 $\mathrm{Fe}_{0.25} \mathrm{P}_{2}$ (111) surface [163]. (C) 2018 WILEY-VCH Verlag GmbH \& Co. KGaA, Weinheim.

question what the OER catalysts really are, especially because catalysis happens on the catalysts surface. Therefore, it is crucial to carry out careful mechanistic studies aided by modern structural or spectroscopic analysis techniques and computational tools to fundamentally understand what are the true catalytically active species on the surface of such claimed OER catalysts of metal chalcogenides and phosphides. Liu et al. [163] recently studied the role of active oxide species for electrochemical water oxidation on the surface of $3 d$-metal phosphides. As shown in Fig. 11, at higher potentials $(1.23$ and 1.60 $\mathrm{V}$ ), the reaction steps of $\mathrm{O}-\mathrm{Ni}_{0.75} \mathrm{Fe}_{0.25} \mathrm{P}_{2}$, except for the third one $\left(\mathrm{O}^{*} \rightarrow \mathrm{HOO}^{*}\right)$, are downhill. This means the partially oxidized surface, namely $0-\mathrm{Ni}_{0.75} \mathrm{Fe}_{0.25} \mathrm{P}_{2}$, would optimize the local chemical environment to recover the reaction of $\mathrm{O}^{*}+\mathrm{HO}^{*} \rightarrow$ HOO* along with the effective free energy and finally accelerate the reaction steps. In another paper, Hu et al. [53] found that the oxidized CoP nanoarray catalyst is much more active than the analogous $\mathrm{Co}_{3} \mathrm{O}_{4}$ nanoarray in OER, and emphasized the CoP core contributes significantly to the activity. These researches reveal that many potential reasons may be responsible for such enhanced catalytic performance. The derived metal oxides/hydroxides could be formed as high surface area nanostructures that could boost the overall performance. During catalytic transformation, the conversion process from the precursor may result in unusual amorphous or metastable metal oxide/hydroxide overlayer on its surface. The new formed surfaces are more catalytically active, otherwise difficult to prepare by conventional synthetic methods. Metal sulfides and phosphides remain as the core and serve as the conductive scaffolds for the active metal oxide/hydroxide species. Besides, the synergistic electronic interactions between the different components and the special catalytic property of M(P or $\mathrm{S})_{x}-\mathrm{MO}_{x}$ interface could make the composite electrocatalysts better than the simple oxides. Another speculation could be that phosphide (or sulfide) are mostly converted to their phosphate (or sulfate), which might have a major influence in the superior activity of the catalysts for OER. The phosphate residue on the surface can act as a labile ligand that possesses the ability to vary its coordination or chelating modes during the redox process of the metal ion and finally facilitates the OER.

However, not all the OER activity of metal phosphide and sulfide are enhanced with the decoration of partially oxidized surface. In a particular case, Brock and co-workers [165] studied the decrease in activity over time for CoMnP. They reported fast leaching of the phosphate ion from the catalyst compared to the metallic leaching. Similar phenomenon was also observed by Peng and coworkers [164] in the case of metal sulfide. There is a $>50 \%$ activity loss in the fully sulfurated $\mathrm{Ni}$ $\mathrm{Co}_{2} \mathrm{~S}_{4}$ over a $30 \mathrm{~h}$ accelerated aging test. The high-resolution XPS spectra of $S 2 p$ (Fig. 12(a)) showed that the sulfur loss for $\mathrm{NiCo}_{2} \mathrm{~S}_{4}$ is up to $85 \%$ after a lengthy OER process. In order to improve the activity and stability of sulfides simultaneously, they further proposed a "dual-ligand synergistic modulation strategy" that is pre-introducing $\mathrm{OH}$ ligand into the metal sulfide to form new sulfhydroxide as OER catalyst. The dual-ligand $\mathrm{NiCo}_{2}(\mathrm{SOH})_{x}$ catalyst exhibits an excellent OER activity with a very small overpotential of $0.29 \mathrm{~V}$ at a current density of $10 \mathrm{~mA}$ $\mathrm{cm}^{-2}$ and a strong durability even after $30 \mathrm{~h}$ accelerated aging at $100 \mathrm{~mA} \mathrm{~cm}-2$, both of which are superior to most of the state-of-the-art OER catalysts so far (Fig. 12(c) and (d)). The density functional theory (DFT) calculations disclose that the synergy of $\mathrm{OH}$ and $\mathrm{S}$ ligands on the surface of $\mathrm{NiCo}_{2}(\mathrm{SOH})_{x}$ delicately optimize binding energies of the OER intermediates 

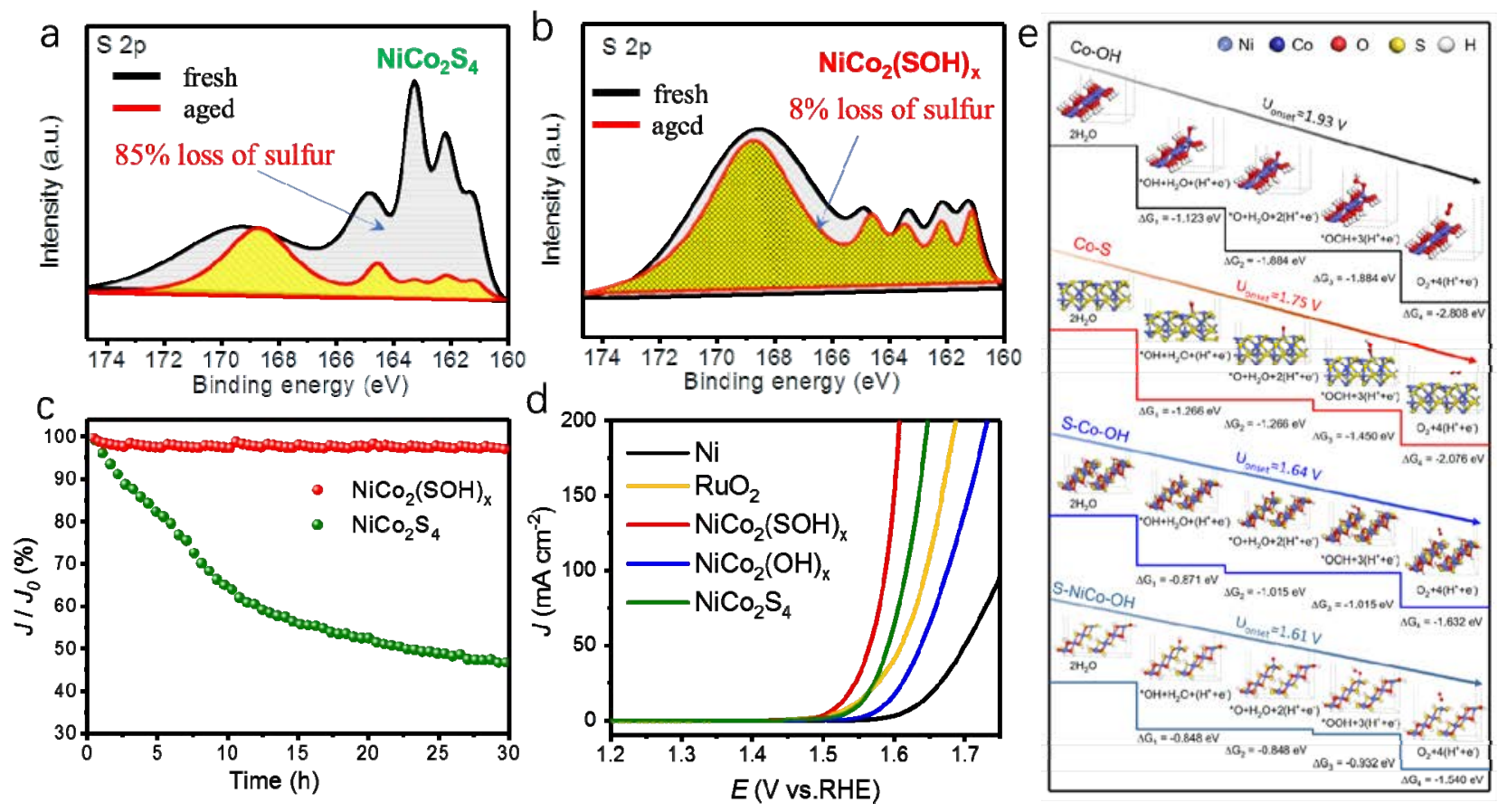

Fig. 12. High resolution S $2 p$ XPS spectra of $\mathrm{NiCo}_{2} \mathrm{~S}_{4}(\mathrm{a})$ and $\mathrm{NiCo}_{2}(\mathrm{SOH})_{x}$ (b) before and after aging. (c) Chronoamperometric curves of $\mathrm{NiCo}_{2}(\mathrm{SOH})_{x}$

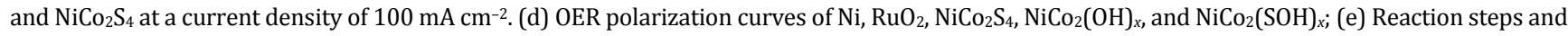
corresponding free energy diagram of the OER process on the pristine Co-OH, S-Co-OH, S-NiCo-OH, and Co-S surfaces at their minimum OER potentials [164]. (C) 2017 American Chemical Society.

$\left({ }^{*} \mathrm{OH},{ }^{*} \mathrm{O}\right.$, and $\left.{ }^{*} \mathrm{OOH}\right)$ and strengthen binding energy between metal and anion ligands, thus leading to an excellent intrinsically enhanced OER activity and stability, respectively. Based on the narration above, we can suggest the complexity in these in situ oxidation processes of phosphide and sulfide materials for OER (Fig. 12(e)).

\section{Conclusions and perspective}

Due to the sluggish reaction kinetics, OER is the bottleneck for electrocatalytic water splitting and decides the overall Faradaic efficiency of the electrolytic cell. Efficient electrocatalysts are required to expedite the reaction and phosphide/sulfide-based materials are promising candidates with low cost and high activity. In this review, we have made a comparative summary of recent progress with transition metal-based sulfide and phosphide catalysts for OER to enable those who are working on increasing the efficiencies of these catalysts for $\mathrm{H}_{2}$ production by electrocatalytic water splitting with little loss in electrical energy via designing catalysts with low overpotentials.

Various efficient tactics have been considered to enhance the performance of non-precious sulfide and phosphide catalysts. The most general tactic is designing and fabricating catalysts with nanostructures to increase the surface area, active sites and surface reaction kinetics. Owing to the fast development of synthetic technique, sulfide and phosphide based materials with various morphologies have been developed. Besides, although phosphide and sulfide are relative good con- ductors, further improvement is imperative for facilitating charge transfer during working condition. Various metal conductive supports and well-designed precursor (such as MOFs) have been employed to incorporate conductive component with active catalysts, and finally enhancing the OER activity. Fine-tuning the crystal structure and exposing high-index crystal plane are more interesting and goal-oriented strategies to obtain high active catalysts, as different crystal structure and plane always possess special chemical catalytic properties. Moreover, tremendous efforts have been devoted to obtaining phosphide and sulfide-based catalysts with better performance by foreign element doping or alloying. High throughput screening analysis has also been developed to select suitable foreign element and its favorable content doping into the host material, and few reports have elaborated the detailed mechanism responsible for the improved activity resulting from foreign element incorporation. Furthermore, as OER occurs at a high potential (above $1.23 \mathrm{~V}$ vs. RHE), the surface of phosphide and sulfide inevitably be oxidized and formed many new component on the catalysts surface. Many reports have confirmed the generation of oxide/hydroxide-based active phase on the catalyst surface after OER by in situ spectroscopy. Mechanistic studies have suggested the modification of structural and electronic properties after catalyst surface modified by derived metal oxides/hydroxides.

Despite the fact that the booming research on metal phosphides and sulfides as water oxidation electrocatalysts has deepened our understanding about metal phosphides and sulfides, there are still many interesting but confusing scientific 
questions need to be resolved with the collective effort of the research community. The mechanism of the promoted performance caused by elemental doping need in-depth studies, as well as the development of more types of doping elements. Besides, the metal phosphides and sulfides with high-active facets have been proven to be more effective OER electrocatalysts, while the synthesis process is too difficult and combining the catalysts (always synthesized as powder) with the self-supported electrodes is still a challenge.

Additionally, although the OER mechanism has been widely studied, the real mechanism of metal phosphides and sulfides for OER have not been fully understood. The in-situ structure reconstruction after the adsorption of various electrochemical intermediates remains shrouded in mystery. We also don't know how the real microscopic interface structure influences the electrode reaction. The true OER-active species of metal phosphides and sulfides are not sure. Most phosphide and sulfide-based materials exhibited apparent activity increasement after continues OER process, while some of them even got worse. The cause of varied OER catalysis after in situ oxidation processes of phosphide and sulfide materials remains unclear, and this should be a focus of future studies. In situ spectroscopy and theoretical calculations show an applied potential to make possible approaches to reveals the internal relation between the in situ oxidation and catalytic activity. With a deep insight into the basic mechanism, new highly efficient and robust OER catalysts will be discovered, and therefore move the field forward to overcome the challenges in developing industrialization progress of water electrolysis.

Author Contributions: Lishan Peng contributed to the conception and the writing of this paper. Zidong Wei and Syed Shoaib Ahmad Shah contributed to the revision of this paper.

\section{References}

[1] S. Chu, Y. Cui, N. Liu, Nat. Mater., 2016, 16, 16-22.

[2] M. Z. Jacobson, W. G. Colella, D. M. Golden, Science, 2005, 308, 1901-1905.
[3] X. Zheng, L. Peng, L. Li, N. Yang, Y. Yang, J. Li, J. Wang, Z. Wei, Chem. Sci., 2018, 9, 1822-1830.

[4] L. Peng, Y. Nie, L. Zhang, R. Xiang, J. Wang, H. Chen, K. Chen, Z. Wei, ChemCatChem, 2017, 9, 1588-1593.

[5] L. Peng, J. Shen, L. Zhang, Y. Wang, R. Xiang, J. Li, L. Li, Z. Wei, J. Mater. Chem. A, 2017, 5, 23028-23034.

[6] Y. Shi, B. Zhang, Chem. Soc. Rev., 2016, 45, 1529-1541.

[7] A. Herzog, N. R. D. Council, M. Tatsutani and Consultant, Natural Resources Defense Council, 2005.

[8] M. Wang, A. Elgowainy, M. Wu, Department of Energy, 2016, http://energy.gov/eere/fuelcells/hydrogen-production-pathways.

[9] H. Dau, C. Limberg, T. Reier, M. Risch, S. Roggan, P. Strasser, ChemCatChem, 2010, 41, 724-761.

[10] N. T. Suen, S. F. Hung, Q. Quan, N. Zhang, Y. J. Xu, H. M. Chen, Chem. Soc. Rev., 2017, 46, 337-365.

[11] H. Over, Chem. Rev., 2012, 112, 3356-3426.

[12] Y. Lee, J. Suntivich, K. J. May, E. E. Perry, S. H. Yang, J. Phys. Chem. Lett., 2012, 3, 399-404.

[13] N. Wang, H. Zheng, W. Zhang, R. Cao, Chin. J. Catal., 2018, 39, 228-244.

[14] Y. Huang, M. Zhang, P. Liu, F. Cheng, L. Wang, Chin. J. Catal., 2016, 37, 1249-1256.

[15] Y. Gao, H. Chen, L. Ye, Z. Lu, Y. Yao, Y. Wei, X. Chen, Chin. J. Catal., 2018, 39, 479-486.

[16] J. L. Luo, Acta Phys. Chim. Sin., 2018, 34, 7-8.

[17] H. Y. Wang, G. Q. Shi, Acta Phys. Chim. Sin., 2018, 34, 22-35.

[18] M. Jiang, J. Chen, Y. Li, Chin. J. Catal., 2018, 39, 1017-1026.

[19] M. Tang, Q. Ge, Chin. J. Catal., 2017, 38, 1621-1628.

[20] F. Lu, M. Zhou, Y. Zhou, X. Zeng, Small, 2017, 13, 20170193.

[21] H. F. Wang, C. Tang, B. Q. Li, Q. Zhang, Inorg. Chem. Front., 2018, 5, 521-534.

[22] B. Xiong, L. Chen, J. Shi, ACS Catal., 2018, 8, 3688-3707.

[23] J. Li, G. Du, X. Cheng, P. Feng, X. Luo, Chin. J. Catal., 2018, 39, 982-987.

[24] X. Leng, K. H. Wu, B. J. Su, L. Y. Jang, I. R. Gentle, D. W. Wang, Chin. J. Catal., 2017, 38, 1021-1027.

[25] A. Dutta, N. Pradhan, J. Phys. Chem. Lett., 2016, 8, 144-152.

[26] Y. Lv, X. Wang, Catal. Sci. Technol., 2017, 7, 3676-3691.

[27] M. R. Gao, Y. F. Xu, J. Jiang, S. H. Yu, Chem. Soc. Rev., 2013, 42, 2986-3017.

[28] F. Wang, T. A. Shifa, X. Zhan, Y. Huang, K. Liu, Z. Cheng, C. Jiang, J. He, Nanoscale, 2015, 7, 19764-19788.

[29] L. Peng, Z. Wei, Prog. Chem., 2018, 14-28.

\section{Graphical Abstract}

Chin. J. Catal., 2018, 39: 1575-1593 doi: 10.1016/S1872-2067(18)63130-4

\section{Recent developments in metal phosphide and sulfide electrocatalysts for oxygen evolution reaction}

Lishan Peng, Syed Shoaib Ahmad Shah, Zidong Wei *

Chongqing University

An overview summarized recent advances in metal phosphide and sulfide-based OER electrocatalysts in terms of their chemical properties, synthetic methodologies, catalytic performances evaluation and improvement strategy, and real active component for OER.
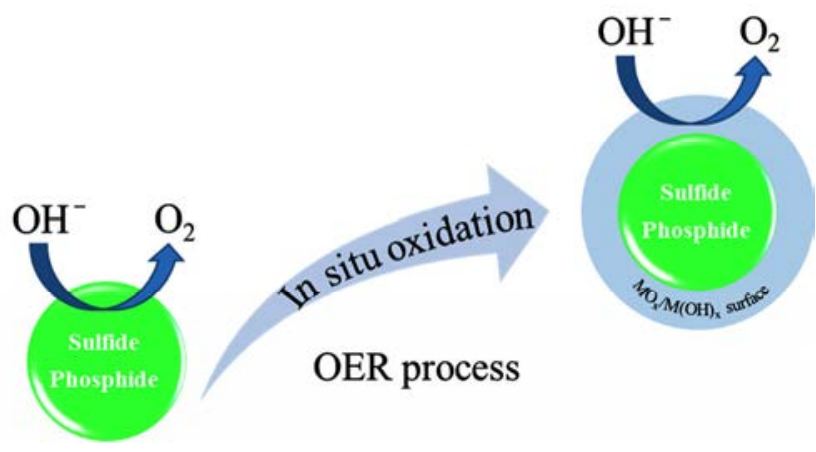
[30] M. Tahir, L. Pan, F. Idrees, X. Zhang, L. Wang, J. J. Zou, Z. L. Wang, Nano Energy, 2017, 37.

[31] M. Gong, H. Dai, Nano Res., 2015, 8, 23-39.

[32] X. Li, X. Hao, A. Abudula, G. Guan, J. Mater. Chem. A, 2016, 4, 11973-12000.

[33] M. Bajdich, M. García-Mota, A. Vojvodic, J. K. Nørskov, A. T. Bell, J. Am. Chem. Soc., 2013, 135, 13521-13530.

[34] E. Fabbri, A. Habereder, K. Waltar, R. Kötz, T. J. Schmidt, Catal. Sci. Technol., 2014, 4, 3800-3821.

[35] Y. Matsumoto, E. Sato, Mater. Chem. Phys., 1986, 14, 397-426.

[36] J. O. Bockris, T. Otagawa, J. Phys. Chem., 1983, 87, 2960-2971.

[37] W. H. Wade, N. Hackerman, Trans. Faraday Soc., 1957, 53, 1636-1647.

[38] I. C. Man, H. Y. Su, F. Calle-Vallejo, H. A. Hansen, J. I. Martínez, N. G. Inoglu, J. Kitchin, T. F. Jaramillo, J. K. Nørskov, J. Rossmeisl, ChemCatChem, 2011, 3, 1159-1165.

[39] S. Anantharaj, S. R. Ede, K. Sakthikumar, K. Karthick, S. Mishra, S. Kundu, ACS Catal., 2016, 6, 8069-8097.

[40] J. Rossmeisl, Z. W. Qu, H. Zhu, G. J. Kroes, J. K. Nørskov, J. Electroanal. Chem., 2007, 607, 83-89.

[41] X. Li, X. Hao, A. Abudula, G. Guan, J. Mater. Chem. A, 2016, 4, 11973-12000.

[42] J. Kupka, A. Budniok, J. Appl. Electrochem., 1990, 20, 1015-1020.

[43] J. Ryu, N. Jung, J. H. Jang, H. J. Kim, S. J. Yoo, ACS Catal., 2015, 5, 4066-4074.

[44] H. Yang, Y. Zhang, F. Hu, Q. Wang, Nano Lett., 2015, 15, 7616-7620.

[45] J. Li, J. Li, X. Zhou, Z. Xia, W. Gao, Y. Ma, Y. Qu, ACS Appl. Mater. Interfaces, 2016, 8, 10826-10834.

[46] M. Liu, J. Li, ACS Appl. Mater. Interfaces, 2016, 8, 2158-2165.

[47] J. Masud, S. Umapathi, N. Ashokaan, M. Nath, J. Mater. Chem. A, 2016, 4, 9750-9754.

[48] H. Jia, R. Jiang, W. Lu, Q. Ruan, J. Wang, J. C. Yu, J. Mater. Chem. A, 2018, 6, 4783-4792.

[49] S. Surendran, S. Shanmugapriya, S. Shanmugam, L. Vasylechko, R. Kalai Selvan, ACS Appl. Energy Mater., 2018, 1, 78-92.

[50] W. Xu, S. Zhu, Y. Liang, Z. Cui, X. Yang, A. Inoue, J. Mater. Chem. A, 2018, 6, 5574-5579.

[51] S. Oh, H. W. Kim, Y. K. Kwon, M. J. Kim, E. A. Cho, H. S. Kwon, J. Mater. Chem. A, 2016, 4, 18272-18277.

[52] P. Li, H. C. Zeng, J. Mater. Chem. A, 2018, 6, 2231-2238.

[53] P. Wang, F. Song, R. Amal, Y. H. Ng, X. Hu, ChemSusChem, 2016, 9, 472-477.

[54] W. Li, X. Gao, D. Xiong, F. Xia, J. Liu, W. G. Song, J. Xu, S. M. Thalluri, M. F. Cerqueira, X. Fu, L. Liu, Chem. Sci., 2017, 8, 2952-2958.

[55] X. Wang, W. Li, D. Xiong, L. Liu, J. Mater. Chem. A, 2016, 4, 5639-5646.

[56] S. Wei, K. Qi, Z. Jin, J. Cao, W. Zheng, H. Chen, X. Cui, ACS Omega, 2016, 1, 1367-1373.

[57] J. Xiao, Q. Lv, Y. Zhang, Z. Zhang, S. Wang, RSC Adv., 2016, 6, 107859-107864.

[58] J. Yu, Q. Li, Y. Li, C. Y. Xu, L. Zhen, V. P. Dravid, J. Wu, Adv. Funct. Mater., 2016, 26, 7644-7651.

[59] Z. Zhang, J. Hao, W. Yang, J. Tang, RSC Adv., 2016, 6, 9647-9655.

[60] S. H. Ahn, A. Manthiram, J. Mater. Chem. A, 2017, 5, 2496-2503.

[61] C. Du, M. Shang, J. Mao, W. Song, J. Mater. Chem. A, 2017, 5, 15940-15949.

[62] A. Han, H. Zhang, R. Yuan, H. Ji, P. Du, ACS Appl. Mater. Interfaces, 2017, 9, 2240-2248.

[63] J. Li, G. Wei, Y. Zhu, Y. Xi, X. Pan, Y. Ji, I. V. Zatovsky, W. Han, J. Mater. Chem. A, 2017, 5, 14828-14837.

[64] M. Qian, S. Cui, D. Jiang, L. Zhang, P. Du, Adv Mater., 2017, 29,
201704075.

[65] Y. Lu, T. Wang, X. Li, G. Zhang, H. Xue, H. Pang, RSC Adv., 2016, 6, 87188-87212.

[66] M. Ledendecker, S. Krick Calderon, C. Papp, H. P. Steinruck, M. Antonietti, M. Shalom, Angew. Chem. Int. Ed., 2015, 54, 12361-12365.

[67] J. Masa, S. Barwe, C. Andronescu, I. Sinev, A. Ruff, K. Jayaramulu, K. Elumeeva, B. Konkena, B. Roldan Cuenya, W. Schuhmann, ACS Energy Lett., 2016, 1, 1192-1198.

[68] B. Zhang, Y. H. Lui, L. Zhou, X. Tang, S. Hu, J. Mater. Chem. A, 2017, 5, 13329-13335.

[69] P. E. R. Blanchard, A. P. Grosvenor, R. G. Cavell, A. Mar, Chem. Mater., 2008, 20, 7081-7088.

[70] Z. Jin, P. Li, D. Xiao, Green Chem., 2016, 18, 1459-1464.

[71] Y. P. Zhu, Y. P. Liu, T. Z. Ren, Z. Y. Yuan, Adv. Funct. Mater., 2015, 25, 7337-7347.

[72] J. Yu, G. Cheng, W. Luo, J. Mater. Chem. A, 2017, 5, 11229-11235.

[73] X. Wang, W. Li, D. Xiong, D. Y. Petrovykh, L. Liu, Adv. Funct. Mater., 2016, 26, 4067-4077.

[74] C. C. Hou, S. Cao, W. F. Fu, Y. Chen, ACS Appl. Mater. Interfaces, 2015, 7, 28412-28419.

[75] C. G. Read, J. F. Callejas, C. F. Holder, R. E. Schaak, ACS Appl. Mater. Interfaces, 2016, 8, 12798-12803.

[76] L. Wei, K. Goh, O. Birer, H. E. Karahan, J. Chang, S. Zhai, X. Chen, Y. Chen, Nanoscale, 2017, 9, 4401-4408.

[77] C. Z. Yuan, S. L. Zhong, Y. F. Jiang, Z. K. Yang, Z. W. Zhao, S. J. Zhao, N. Jiang, A. W. Xu, J. Mater. Chem. A, 2017, 5, 10561-10566.

[78] L. Xie, R. Zhang, L. Cui, D. Liu, S. Hao, Y. Ma, G. Du, A. M. Asiri, X. Sun, Angew. Chem. Int. Ed., 2017, 56, 1064-1068.

[79] C. C. Hou, Q. Q. Chen, C. J. Wang, F. Liang, Z. Lin, W. F. Fu, Y. Chen, ACS Appl. Mater. Interfaces, 2016, 8, 23037-23048.

[80] D. Xiong, X. Wang, W. Li, L. Liu, Chem. Commun., 2016, 52, 8711-8714.

[81] Z. Zhang, S. Liu, J. Xiao, S. Wang, J. Mater. Chem. A, 2016, 4, 9691-9699.

[82] Y. Yan, B. Y. Xia, X. Ge, Z. Liu, A. Fisher, X. Wang, Chem. Eur. J., 2015, 21, 18062-18067.

[83] X. D. Wang, H. Y. Chen, Y. F. Xu, J. F. Liao, B. X. Chen, H. S. Rao, D. B. Kuang, C. Y. Su, J. Mater. Chem. A, 2017, 5, 7191-7199.

[84] Y. Yan, B. Zhao, S. C. Yi, X. Wang, J. Mater. Chem. A, 2016, 4, 13005-13010.

[85] J. Li, M. Yan, X. Zhou, Z. Q. Huang, Z. Xia, C. R. Chang, Y. Ma, Y. Qu, Adv. Funct. Mater., 2016, 26, 6785-6796.

[86] J. B. Gerken, S. E. Shaner, R. C. Massé, N. J. Porubsky, S. S. Stahl, Energy Environ. Sci., 2014, 7, 2376-2382.

[87] R. Zhang, C. Tang, R. Kong, G. Du, A. M. Asiri, L. Chen, X. Sun, Nanoscale, 2017, 9, 4793-4800.

[88] J. Xu, J. P. S. Sousa, N. E. Mordvinova, J. D. Costa, D. Y. Petrovykh, K. Kovnir, O. I. Lebedev, Y. V. Kolen'ko, ACS Catal., 2018, 8, 2595-2600.

[89] D. Li, H. Baydoun, B. Kulikowski, S. L. Brock, Chem. Mater., 2017, 29, 3048-3054.

[90] J. Xu, X. K. Wei, J. D. Costa, J. L. Lado, B. Owens-Baird, L. P. L. Gonçalves, S. P. S. Fernandes, M. Heggen, D. Y. Petrovykh, R. E. Dunin-Borkowski, K. Kovnir, Y. V. Kolen'ko, ACS Catal., 2017, 7, 5450-5455.

[91] X. Zhang, X. Zhang, H. Xu, Z. Wu, H. Wang, Y. Liang, Adv. Funct. Mater., 2017, 27, 201606635.

[92] P. Wang, Z. Pu, Y. Li, L. Wu, Z. Tu, M. Jiang, Z. Kou, I. S. Amiinu, S. Mu, ACS Appl. Mater. Interfaces, 2017, 9, 26001-26007.

[93] J. Chen, Y. Li, G. Sheng, L. Xu, H. Ye, X. Z. Fu, R. Sun, C. P. Wong, ChemCatChem, 2018, 10, 2248-2253. 
[94] Q. Zhang, D. Yan, Z. Nie, X. Qiu, S. Wang, J. Yuan, D. Su, G. Wang, Z. Wu, ACS Appl. Energy Mater., 2018, 1, 571-579.

[95] F. Li, Y. Bu, Z. Lv, J. Mahmood, G. F. Han, I. Ahmad, G. Kim, Q. Zhong, J. B. Baek, Small, 2017, 13.

[96] K. Liu, C. Zhang, Y. Sun, G. Zhang, X. Shen, F. Zou, H. Zhang, Z. Wu, E. C. Wegener, C. J. Taubert, J. T. Miller, Z. Peng, Y. Zhu, ACS Nano, 2018, 12, 158-167.

[97] Y. Shi, B. Zhang, Dalton Trans., 2017, 46, 16770-16773.

[98] Z. Li, X. Dou, Y. Zhao, C. Wu, Inorg. Chem. Front., 2016, 3, 1021-1027.

[99] B. Y. Guan, L. Yu, X. W. Lou, Angew. Chem. Int. Ed., 2017, 56, 2386-2389.

[100] D. D. Babu, Y. Huang, G. Anandhababu, M. A. Ghausi, Y. Wang, ACS Appl. Mater. Interfaces, 2017, 9, 38621-38628.

[101] L. A. Stern, L. Feng, F. Song, X. Hu, Energy Environ. Sci., 2015, 8, 2347-2351.

[102] J. Chang, Y. Xiao, M. Xiao, J. Ge, C. Liu, W. Xing, ACS Catal., 2015, 5, 6874-6878.

[103] A. Dutta, A. K. Samantara, S. K. Dutta, B. K. Jena, N. Pradhan, ACS Energy Lett., 2016, 1, 169-174.

[104] B. Song, K. Li, Y. Yin, T. Wu, L. Dang, M. Cabán-Acevedo, J. Han, T. Gao, X. Wang, Z. Zhang, J. R. Schmidt, P. Xu, S. Jin, ACS Catal., 2017, 7, 8549-8557.

[105] C. H. Lai, M. Y. Lu, L. J. Chen, J. Mater. Chem., 2012, 22, 19-30.

[106] L. Ran, J. Duay, B. L. Sang, Chem. Commun., 2011, 47, 1384.

[107] C. Burda, X. Chen, A. R. Narayanan, M. A. EI-Sayed, Chem. Rev., 2005, 36, 1025-1102.

[108] P. Kulkarni, S. K. Nataraj, R. G. Balakrishna, D. H. Nagaraju, M. V. Reddy, J. Mater. Chem. A, 2017, 5, 22040-22094

[109] X. Wu, X. Han, X. Ma, W. Zhang, Y. Deng, C. Zhong, W. Hu, ACS Appl. Mater. Interfaces, 2017, 9, 12574-12583.

[110] J. S. Chen, J. Ren, M. Shalom, T. Fellinger, M. Antonietti, ACS Appl. Mater. Interfaces, 2016, 8, 5509-5516.

[111] J. T. Ren, Z. Y. Yuan, ACS Sustain. Chem. Eng., 2017, 5, 7203-7210.

[112] H. Liang, W. Shuang, Y. Zhang, S. Chao, H. Han, X. Wang, H. Zhang, L. Yang, ChemElectroChem, 2018, 5, 494

[113] M. Zhu, Z. Zhang, H. Zhang, H. Zhang, X. Zhang, L. Zhang, S. Wang, J. Colloid. Interface Sci., 2018, 509, 522-528.

[114] J. Wang, H. X. Zhong, Z. L. Wang, F. L. Meng, X. B. Zhang, ACS Nano, 2016, 10, 2342-2348.

[115] T. Liu, Y. Liang, Q. Liu, X. Sun, Y. He, A. M. Asiri, Electrochem. Commun., 2015, 60, 92-96.

[116] J. Jiang, S. Lu, H. Gao, X. Zhang, H. Q. Yu, Nano Energy, 2016, 27, 526-534

[117] A. Sivanantham, P. Ganesan, S. Shanmugam, Adv. Funct. Mater., 2016, 26, 4661-4672.

[118] C. Shu, Y. Liu, J. Long, X. Chen, Y. Su, Part. Part. Syst. Char., 2018, 35, 1700433/1-1700433/9.

[119] X. Feng, Q. Jiao, T. Liu, Q. Li, M. Yin, Y. Zhao, H. Li, C. Feng, W. Zhou, ACS Sustain. Chem. Eng., 2017, 6, 1863-1871.

[120] Y. Zhang, S. Chao, X. Wang, H. Han, Z. Bai, L. Yang, Electrochim. Acta, 2017, 246, 380-390.

[121] Y. Liu, C. Xiao, M. Lyu, Y. Lin, W. Cai, P. Huang, W. Tong, Y. Zou, Y. Xie, Angew. Chem. Int. Ed., 2015, 54, 11231-11235.

[122] M. Chauhan, K. P. Reddy, C. S. Gopinath, S. Deka, ACS Catal., 2017, 7, 5871-5879.

[123] J. Pal, T. Pal, Nanoscale, 2015, 7, 14159-14190.

[124] Y. Sun, C. Liu, D. C. Grauer, J. Yano, J. R. Long, P. Yang, C. J. Chang, J. Am. Chem. Soc., 2013, 135, 17699-17702.

[125] G. Liu, H. G. Yang, J. Pan, Y. Q. Yang, G. Q. Lu, H. M. Cheng, Chem. Rev., 2014, 114, 9559-9612.

[126] J. P. Jacobs, A. Maltha, J. G. H. Reintjes, J. Drimal, V. Ponec, H. H.
Brongersma, J. Catal., 1994, 147, 294-300.

[127] H. Knözinger, P. Ratnasamy, Catal. Rev., 2007, 17, 31-70.

[128] L. L. Feng, G. Yu, Y. Wu, G. D. Li, H. Li, Y. Sun, T. Asefa, W. Chen, X Zou, J. Am. Chem. Soc., 2015, 137, 14023-14026.

[129] X. Ma, W. Zhang, Y. Deng, C. Zhong, W. Hu, X. Han, Nanoscale, 2018, 10, 4816-4824.

[130] S. Ni, X. Yang, T. Li, J. Mater. Chem., 2012, 22, 2395-2397.

[131] J. Yang, X. Duan, Q. Qin, W. Zheng, J. Mater. Chem. A, 2013, 1, 7880-7884.

[132] X. Sun, J. Dou, F. Xie, Y. Li, M. Wei, Chem. Commun., 2014, 50, 9869-9871.

[133] J. Yang, C. Bao, K. Zhu, T. Yu, F. Li, J. Liu, Z. Li, Z. Zou, Chem. Commun., 2014, 50, 4824-4826.

[134] Y. Wang, Q. Zhu, L. Tao, X. Su, J. Mater. Chem., 2011, 21, 9248-9254.

[135] Y. Liu, Y. Li, H. Kang, T. Jin, L. Jiao, Mater. Horiz., 2016, 3, 402-421.

[136] P. Luo, H. Zhang, L. Liu, Y. Zhang, J. Deng, C. Xu, N. Hu, Y. Wang, ACS Appl. Mater. Interfaces, 2017, 9, 2500-2508.

[137] J. Kim, H. Jin, A. Oh, H. Baik, S. H. Joo, K. Lee, Nanoscale, 2017, 9, 15397-15406.

[138] H. Liu, F. X. Ma, C. Y. Xu, L. Yang, Y. Du, P. P. Wang, S. Yang, L. Zhen, ACS Appl. Mater. Interfaces, 2017, 9, 11634-11641.

[139] L. An, P. Zhou, J. Yin, H. Liu, F. Chen, H. Liu, Y. Du, P. Xi, Inorg. Chem., 2015, 54, 3281-3289.

[140] H. Yang, C. Wang, Y. Zhang, Q. Wang, Small, 2018, 14, 1703273.

[141] X. Wu, B. Yang, Z. Li, L. Lei, X. Zhang, RSC Adv., 2015, 5, 32976-32982.

[142] L. Yang, M. Gao, B. Dai, X. Guo, Z. Liu, B. Peng, Electrochim. Acta, 2016, 191, 813-820.

[143] Q. Li, X. Wang, K. Tang, M. Wang, C. Wang, C. Yan, ACS Nano, 2017, 11, 12230-12239.

[144] H. Liu, Q. He, H. Jiang, Y. Lin, Y. Zhang, M. Habib, S. Chen, L. Song, ACS Nano, 2017, 11, 11574-11583.

[145] N. Cheng, Q. Liu, A. M. Asiri, W. Xing, X. Sun, J. Mater. Chem. A, 2015, 3, 23207-23212.

[146] X. Shang, K. L. Yan, S. S. Lu, B. Dong, W. K. Gao, J. Q. Chi, Z. Z. Liu, Y. M. Chai, C. G. Liu, J. Power Sources, 2017, 363, 44-53.

[147] L. Hui, Y. Xue, D. Jia, Z. Zuo, Y. Li, H. Liu, Y. Zhao, Y. Li, ACS Appl. Mater. Interfaces, 2018, 10, 1771-1780.

[148] P. Cai, J. Huang, J. Chen, Z. Wen, Angew. Chem. Int. Ed., 2017, 56, 4858-4861.

[149] J. Hao, W. Yang, Z. Peng, C. Zhang, Z. Huang, W. Shi, ACS Catal., 2017, 7, 4214-4220.

[150] U. K. Sultana, T. He, A. Du, A. P. O'Mullane, RSC Adv., 2017, 7 , 54995-55004.

[151] Y. Jin, X. Yue, H. Du, K. Wang, S. Huang, P. K. Shen, J. Mater. Chem. A, 2018, 6, 5592-5597.

[152] Z. Dai, H. Geng, J. Wang, Y. Luo, B. Li, Y. Zong, J. Yang, Y. Guo, Y. Zheng, X. Wang, Q. Yan, ACS Nano, 2017, 11, 11031-11040.

[153] C. Ray, S. C. Lee, K. V. Sankar, B. Jin, J. Lee, J. H. Park, S. C. Jun, ACS Appl. Mater. Interfaces, 2017, 9, 37739-37749.

[154] F. Zhang, Y. Ge, H. Chu, P. Dong, R. Baines, Y. Pei, M. Ye, J. Shen, ACS Appl. Mater. Interfaces, 2018, 10, 7087-7095.

[155] S. Jin, ACS Energy Lett., 2017, 2, 1937-1938.

[156] A. Han, H. Chen, Z. Sun, J. Xu, P. Du, Chem. Commun., 2015, 51, 11626-11629.

[157] W. Chen, H. Wang, Y. Li, Y. Liu, J. Sun, S. Lee, J. S. Lee, Y. Cui, ACS Cent. Sci., 2015, 1, 244-251.

[158] O. Mabayoje, A. Shoola, B. R. Wygant, C. B. Mullins, ACS Energy Lett., 2016, 1, 195-201. 
[159] M. Xie, S. Ai, J. Yang, Y. Yang, Y. Chen, Y. Jin, ACS Appl. Mater. Interfaces, 2015, 7, 17112-17121.

[160] K. Xu, H. Cheng, L. Liu, H. Lv, X. Wu, C. Wu, Y. Xie, Nano Lett., 2017, 17, 578-583.

[161] M. Zhou, Q. Weng, X. Zhang, X. Wang, Y. Xue, X. Zeng, Y. Bando, D. Golberg, J. Mater. Chem. A, 2017, 5, 4335-4342.

[162] K. Xiong, L. Huang, Y. Gao, H. Zhang, Y. Zhuo, H. Shen, Y. Wang, L.
Peng, Z. Wei, Electrochem. Commun., 2018, 92, 9-13.

[163] K. Liu, F. Wang, P. He, T. A. Shifa, Z. Wang, Z. Cheng, X. Zhan, J. He, Adv. Energy Mater., 2018, 8, 1703290.

[164] L. Peng, J. Wang, Y. Nie, K. Xiong, Y. Wang, L. Zhang, K. Chen, W. Ding, L. Li, Z. Wei, ACS Catal., 2017, 7, 8184-8191.

[165] D. Li, H. Baydoun, C. N. Verani, S. L. Brock, J. Am. Chem. Soc., 2016, 138, 4006-4009.

\title{
电催化析氧反应过渡金属磷化物和硫化物催化剂研究进展 \\ 彭立山, Syed Shoaib Ahmad Shah，魏子栋* \\ 重庆大学化学化工学院, 重庆400044
}

\begin{abstract}
摘要: 对化石能源的依赖所造成的环境污染和能源危机在全球引起了广泛的关注. 氢能由于其高能量密度、低分子质量以 及清洁无污染的优点, 被认为是人类根本性解决能源与环境等全球性问题的理想替代能源. 电解水是生产高纯度氢的重 要方法, 是现代清洁能源技术的重要组成部分. 水电解由阴极析氢(HER)和阳极析氧(OER)两个半反应构成. 对于HER反 应, 其反应是基于二电子转移过程, 反应过程相对容易进行. 相比于HER反应, OER 反应涉及四电子转移及氧-氧键形成, 其反应动力学缓慢, 是影响水电解效率的主要原因. 因此, 为了提高电解水制氢的能量转化效率, 发展 OER电催化剂成为 水电解制氢技术的关键. 在过去的十余年间, 硫化物、硒化物、磷化物、嗍化物等非贵金属基OER电催化剂被大量地研究 及报道并取得了长足发展. 在这些催化剂中, 金属磷化物和硫化物不仅具有成本优势, 而且在析氧过电位、耐久性方面正 趋接近甚至超越 $\mathrm{RuO}_{2}$ 和 $\mathrm{IrO}_{2}$ 等贵金属催化剂, 颇具应用潜力. 本文总结磷化物和硫化物作为OER电催化剂的研究进展, 重 点介绍了磷化物和硫化物性能提升策略及其在OER过程中催化反应活性位的变化.

本文首先介绍了电解水析氧反应在不同电解质中的反应机理, 讨论了析氧反应在动力学和热力学过程的主要障碍. 通过对大量文献的归纳, 本文分别综述了磷化物和硫化物的化学性质、合成方法和催化性能, 介绍了近年来磷化物和硫化 物的重要研究进展. 通过分析催化剂导电性、质子传输、活性面积、界面化学等因素对催化析氧反应的影响, 总结了磷化 物和硫化物电催化OER性能提升的策略. 由于磷化物和硫化物在OER强氧化条件下, 电催化剂表面的成分、物相及结构均 会发生显著变化, 进而催化反应活性位也会发生相应改变. 本文综述了磷化物和硫化物在OER反应过程前后表面组分的 变化, 探讨了磷化物和硫化物作为OER电催化剂的活性组分, 为进一步提高磷化物和硫化物的电催化析氧反应性能提供了 崭新的思路.
\end{abstract}

关键词: 析氧反应; 电催化剂; 金属磷化物; 金属硫化物; 原位氧化; 活性组分

收稿日期: 2018-05-30. 接受日期: 2018-07-03. 出版日期: 2018-10-05.

*通讯联系人. 电话: (023)65678928; 电子信箱: zdwei@cqu.edu.cn

基金来源：国家重点研究发展计划(2016YFB0101202); 国家自然科学基金重点项目(91534205, 21376283, 21576032).

本文的电子版全文由Elsevier出版社在ScienceDirect上出版(http://www.sciencedirect.com/science/journal/18722067). 